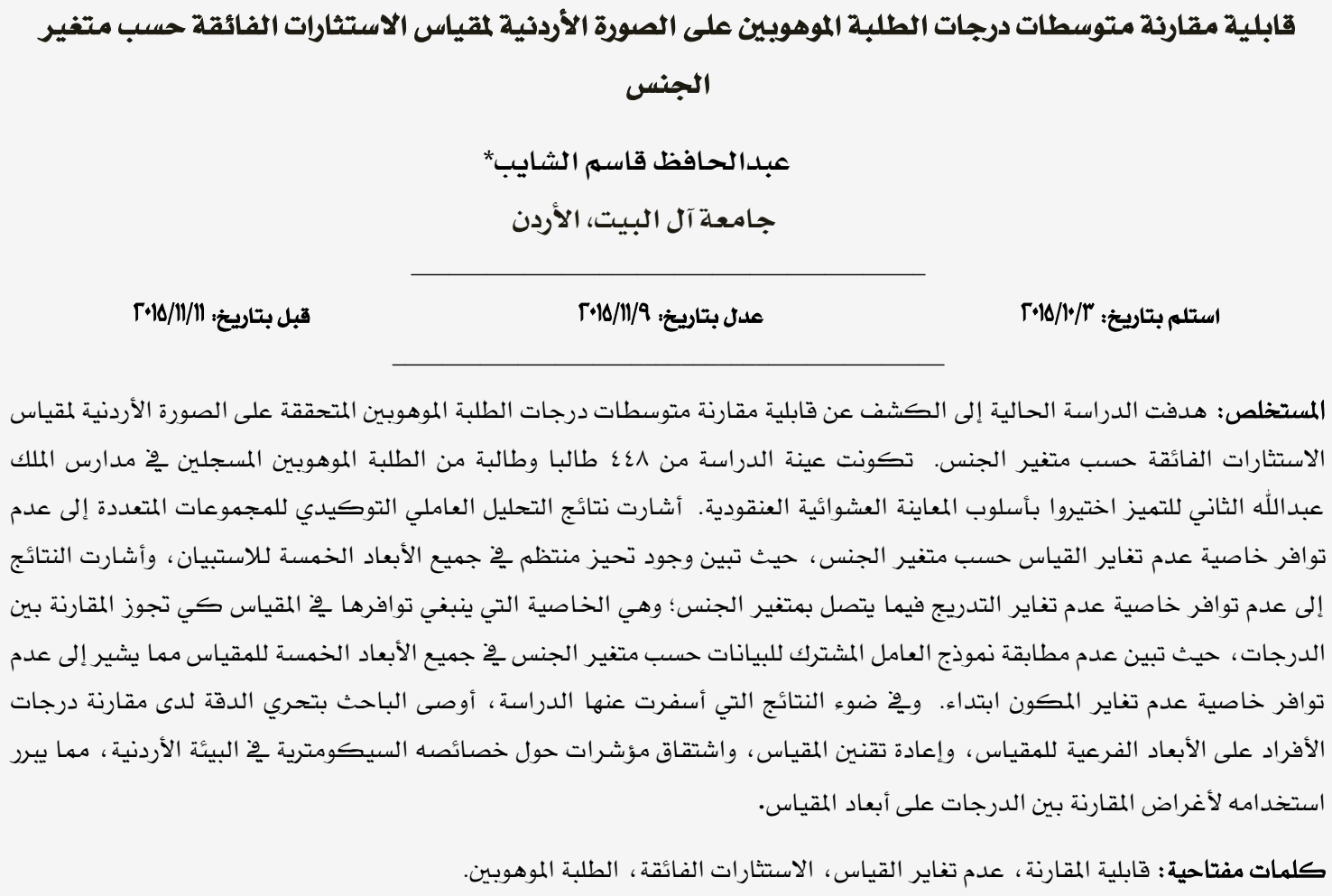

\title{
Comparability of Mean Scores of Gifted Students on the Jordanian Version of the Overexcitability Questionnaire (OEQII) Across Gender
}

Abdelhafez Q. Al-Shayeb*

Al Al-Bayt University, Jordan

\begin{abstract}
The aim of the present study was to investigate the comparability of the mean scores of gifted students on the Jordanian version of the Overexcitabilities Questionnaire OEQII in light of gender. A cluster random sampling technique was used to collect data from 448 males and females gifted students who are enrolled in the King Abdullah II Schools of Excellence in Jordan. Results of multi-group confirmatory factor analysis clearly indicate that measurement invariance with respect to gender is untenable. Uniform measurement bias was observed in all subscales. Results suggested that the Jordanian version of OEQII failed to display scalar invariance across gender which is a requirement to scores' comparability. Initial analyses of fitting the model to the data for each subscale suggested that the theoretical common factor structure didn't display a reasonable fit to the data for any subscale. Results suggested that the Jordanian version of OEQII failed initially to display configural invariance across gender. In light of the results, it is recommended that the mean-level comparisons of OEQII subscale scores across gender should be interpreted with caution. Moreover, re-validating and restandardizing of the Jordanian version of OEQII was suggested to justify mean scores comparability on its subscales.
\end{abstract}

Keywords: Comparability, measurement invariance, overexitability, gifted students.

*alshayeb99@yahoo.com 
تطور المكون الانفعالي، وأطلق عليها مفهوم:

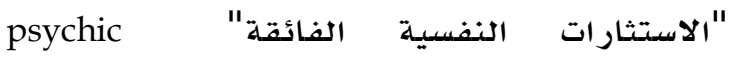
overexcitabilities intellectual overexcitabilities (INOE)

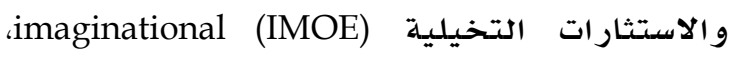

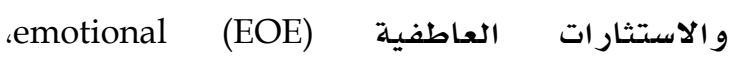
و والاستثارات الحسية (SOEsual (SOE)، والاستثار ات الاستفات النفس حركية (Tieso, psychomotor (POE) .2007a)

من جانب ثان، حدد دابروسكي (Dabrowski) في نظريته ثلاث فئات من العوامل التي تؤثر في دابل في في نهم

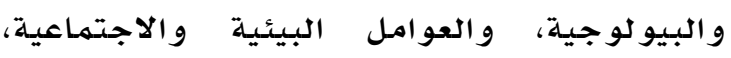

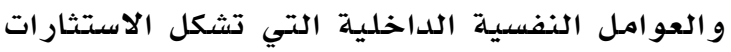

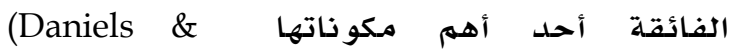
م ونتيجة لتباين العوامل :Piechowsky, 2009b) الوراثية و البيئية والنفسية، فإن الأفراد يتباينون

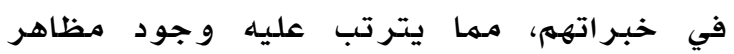

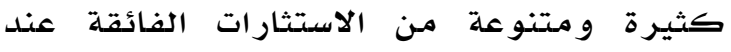

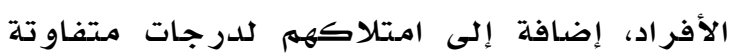
من الاستثار ات الفائقة (Warne, 2011).

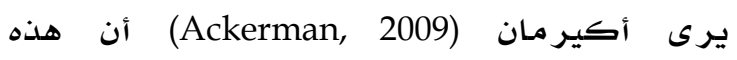

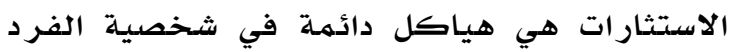
يمكنه من خلالها تمييز المثيرات الخارجية.

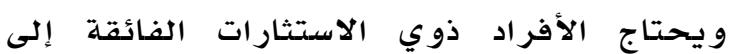

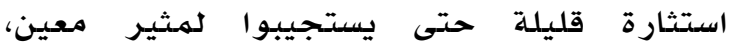
بالإضافة إلى أن ردود أفعالهم تكون قوية تجاه

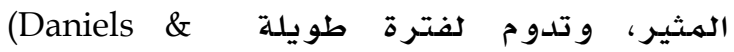

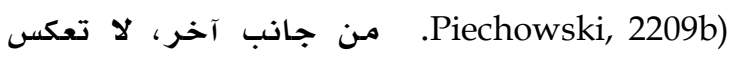

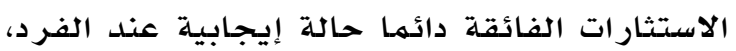
و إنما قد تكون حالة سلبية عنده لدى استحضاره

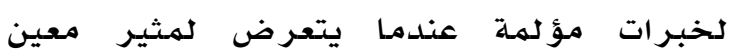

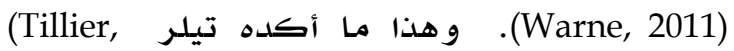
2009, p. 124) بوصفه للاستثارات الفائقة بأنها تلان "هدية مأساوية" tragic gift؛ لأنها تضخم الفانقة بأنها

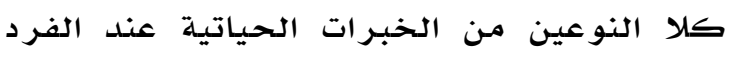
سواء كانت الخبرات سارة أم مؤلمـة".

تعد الاستثارات العقلية الفائقة المظهر البارز

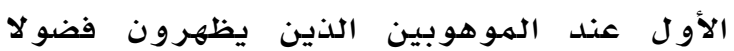

امتد الجدل حول طبيعة سمات الذكاء،

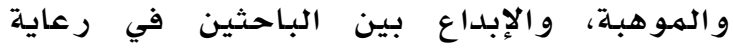

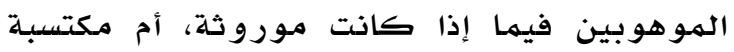
إلى أكثر من قرن ونصف؛ مما دفعهم إلى

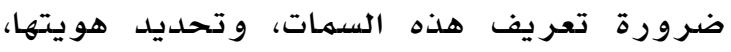
و البحث عن أساليب لكثف عن الموهو تعربين

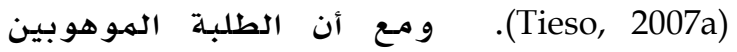

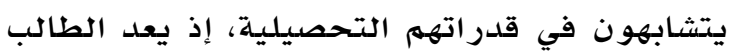

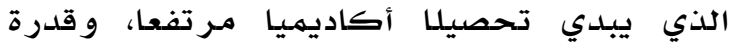

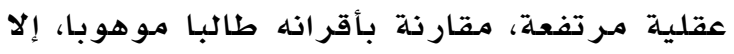
أنهم ليسوا بالضرورة متتشابهين في خصائصهم

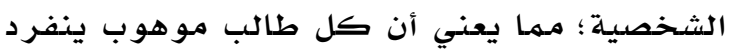
بخصائص ذهنية، وجسمية، واجتماعية، و انفعالية

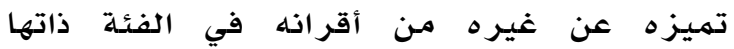
.(Daniels \& Meckstrouth, 2009)

لقد استحوذ المكون الانفعالي للشخصية على

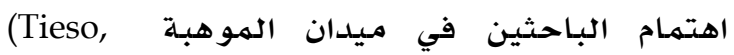

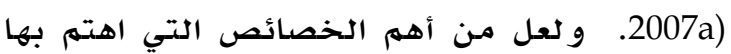

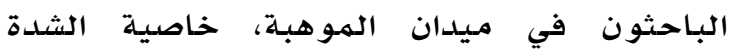

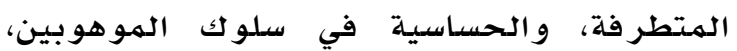

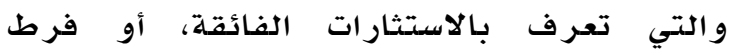

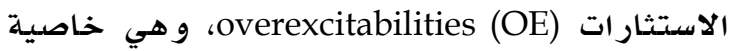

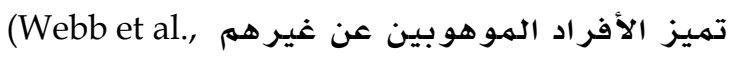
.2005)

يعد الطبيب و عالم النفس البولندي دابروسكي أول من قدم مفهوم الاستثارات (Dabrowski) النفسية الفائقة عام (197v) من القرن من مفر الماضي (Daniels \& Piechowski, 2009a) positive المفهوم ضمن نظرية الانقسام الإيجابي disintegration دابروسكي، ولفتت أنظار المشتغلين في علهم

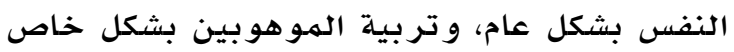
.(Warne, 2011)

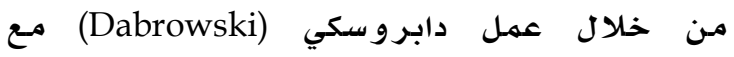
المهوهوبين كبار السن في ظروف ضاغطة في في

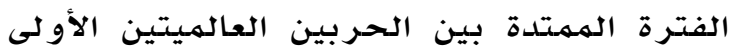

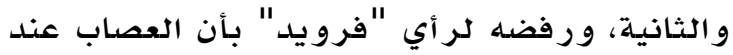
كبار السن ناتج عن الصدمات النفسية في فراني

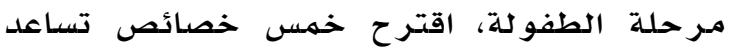
تعرف الحد الذي يمكن أن يرقى إليه الفرد في 


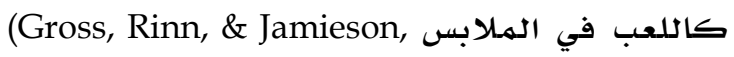

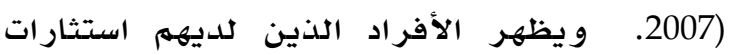
حسية فائقة تقديرا لكلأشياء الجميللة، والأصوات،

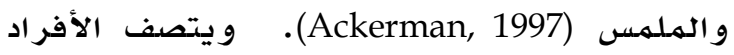
الذين لديهم استثارات نفس حركية فائقة بفائض مـ الطاقة التي تتمثل في حب الحركة،

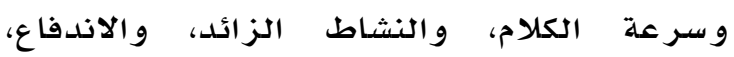

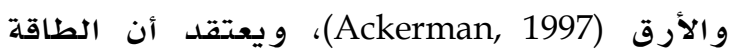
الفائضة تنتج عن التوتر الانفعالي أو النفسي (Daniels \& Piechowski, 2009b) السياق، يحذر وورن (Warne, 2011) من الخلط بين مظاهر الاستثارات النفس حروكية الفور الفائقة

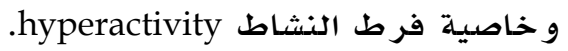

يتفق معظم المشتغلين في ميدان المـوهوبة حول أهمية مفهوم الاستثارات الفائقة في تفسير طيف

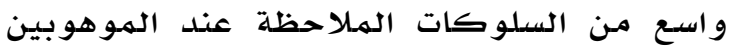

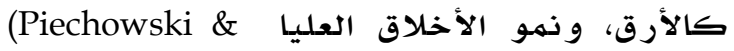

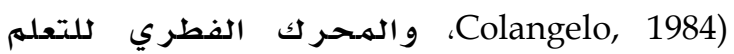
(Ackerman, 1997)، و الحساسية للبيئة الخارجية ولهرية

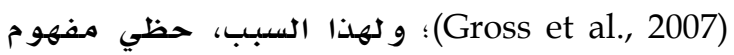
الاستثارات الفائقة بـاهتمام المشتغلين في ميدابل فيدان المـوهبة، و توظيفه في الكثف عن المـوهوبين من

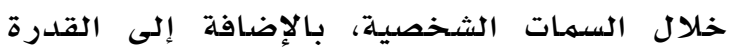

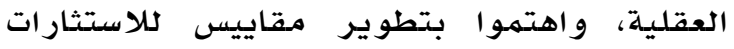

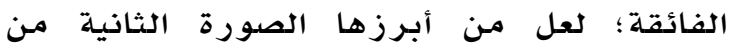

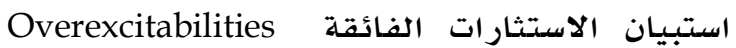
م. و وقد تكون الاستبيان من (0.0) فقرة تتطلب مـن المفحوص الإجابة

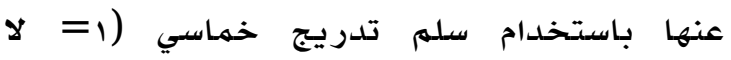
تنطبق إطلاقا، r= لا تنطبق كثيرا، r= إلى حد ما، ع= تنطبق كثير ا، $=$ جدا)، و تتوزع جالتسـاوي على خمسـة أبعاد فرعية

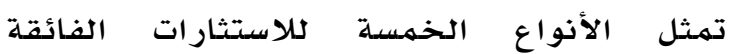

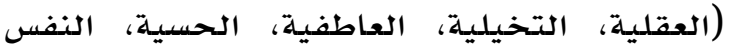

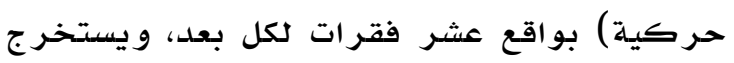
للمفحوص خمس درجات فرعية تمثل الأبعاد (Falk, Lind, Miller, Piechowski, \& الخمسية، و وقد قام فولك وزملامؤه Silverman, 1999) بتطوير الصورة الثانية من استبيان (Falk, et al.)

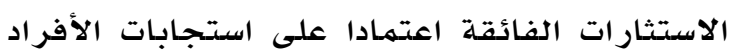

زائدا، ونشاطا عقليا دائما، ويربطون بين

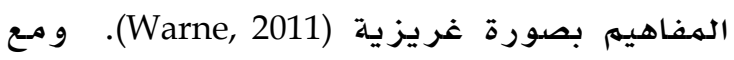

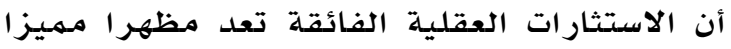

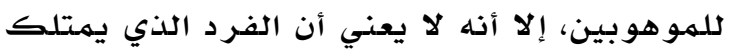
هذا المظهر يمتلك درجة مرتفعة من الذكاء؛ فبينهما تعد قدرة الفرد على حل المسائل الرياضية مؤشرا على ذكائه، تعد رغبته في حل الهسائل الرياضية، وو لعهله بحل المشكلات، وتميزه بنشاط عقلي كبير مؤشرا على وجود الاستثار ات ات العقلية الفائقة عنده Ackerman, 1997; Daniels

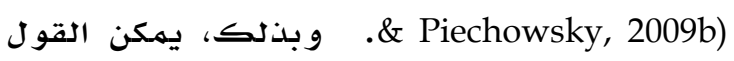
أن الاستثارات العقلية الفائقة هي سمة شخدية شهية

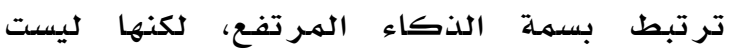

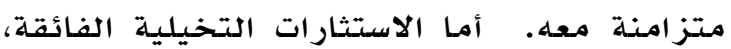
فتعد المظهر الثاني المهميز للموهوبين Boucher)

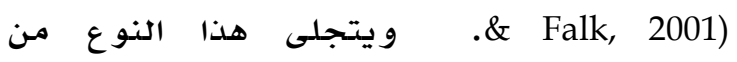
الاستثارات في أحلام اليقظة، والتخيل، والتمثيل

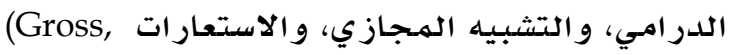

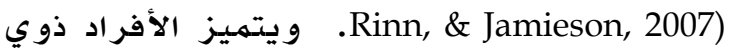
الاستثارات التخيلية الفائقة بأذهم يبتدعون عالم

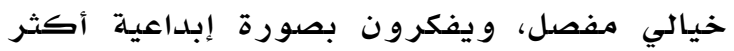

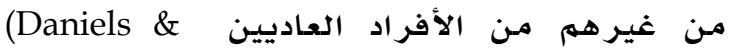

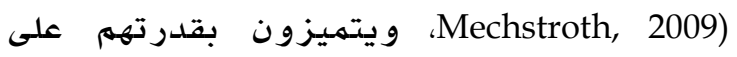
التفكير المهازي الحي، والتمليات التفكير

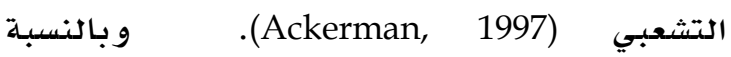

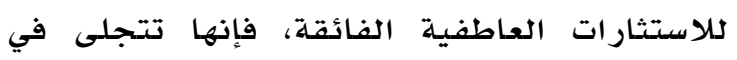
عمق الانفعالات وشدتها التي تظهر من خلارل

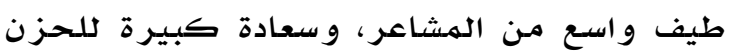
العميق أو اليأس، و الثفقة، والهسؤو لية مaniels) \& Piechowski, 2009b) الاستثارات العاطفية الفائقة بكونه أكثر وعيا ولهير

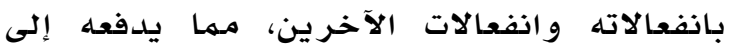

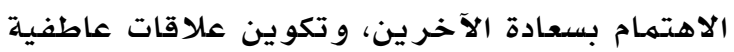
عميقة، وشعور قوي تجاه العدالة الأخلاقية

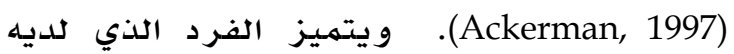
استثارات حسية فائقة بردود أفعال قوية - سواء كانت إيجابية أم سلبية - تجاه المثيرات الحسية،

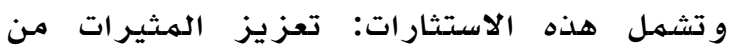
خلال السعي لتصبح مثار الاهتمام كالانغماس

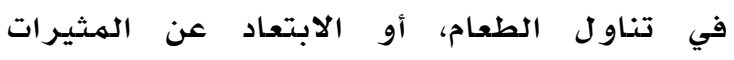


المختلفة و تفسير ها يحتم إجر اء المقارنات بين

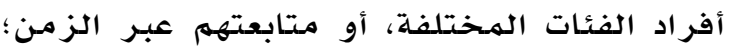

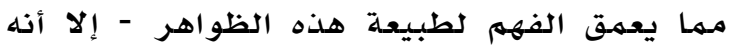
و لسوء الحظ - لا تقوم معظم هذه الهقارنات على أسـاس سليم؛ لأنها تفترض أن أن أدوات القياس

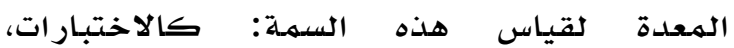
و المقاييس، والاستبيانات،...الخ تقيس المفهوم ذاته عند المجموعات المختلفة. وحتى وحتى تكون درجات الأفراد في المجهموعات المـختلفة قابلة

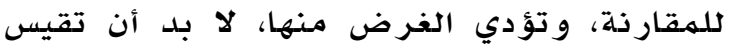

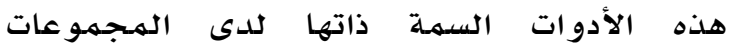

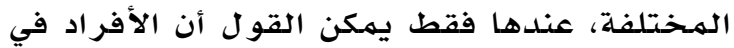
الهمجموعات المـختلفة لا يختلفون فيما بينهم

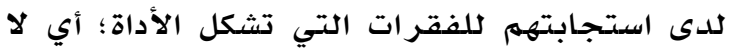

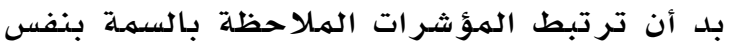
الطريقة في مجمهوعات المقارنة، أو بمعنى أدق، أن تكون السمة الكامنة ذاتها أو العوامل التي

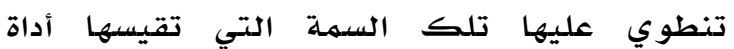
القياس هي التي تفسر الاستجابة لفقرات الأداة

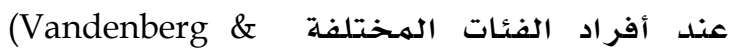
Lance, 2000; Cheung \& Rensvold, 1999; Byrne, Shavelson, \& Muthén, 1989) لا بد أن ترتبط الدرجات المتحققة على مقياس

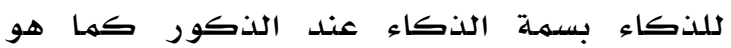
الحال عند الإناث حتى تجوز الهقارنة بين سمة

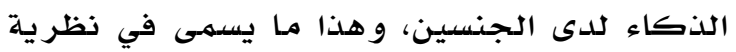

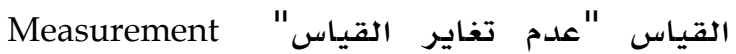
" Invariance (MI) equivalence of measures يطلق البعض على مفهوم عدم تغاير القياس

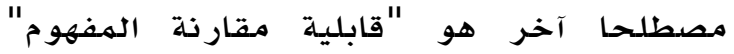
construct comparability صدق الأداة الذي يتطلب أن تقيس درجات الأفراد

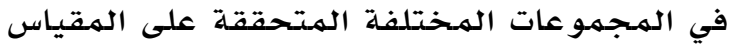
الهفهوم ذاته، عندها فقط يمكن أن تعكس الفروق بين درجات الأفر اد على الهقياس في الهـجموعات

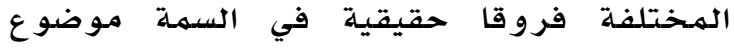
القياس، ويكون عزو هذه الفروق إلى اختلاف

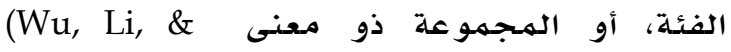

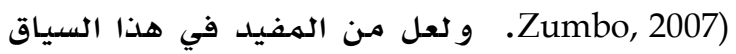
اقتباس ما ذكره زمبو (Zumbo, 2007) - كما
الهفتوحة لفقرات الصورة الأولى لكلاستبيان (OEQ)

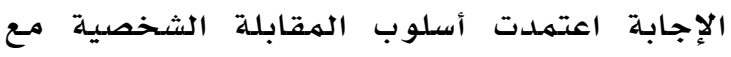

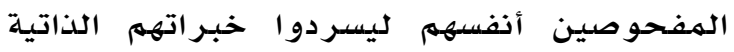
(Piechowski, Silverman, \& Falk, 1985) قام بتعديلها فيما بعد أكير مان (Ackerman) و و

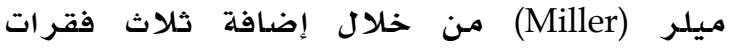

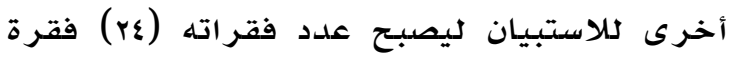
مفتوحة الإجابة (Ackerman \& Miller, 1997). لقد برزت الحاجة لتطوير الصورة الثانية من الدات الاستبيان بسبب صعوبات تصديح إجابات المفحوصين عن فقرات الصورة الأولى التي

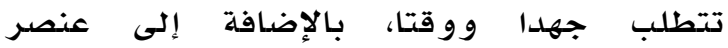
الموضدوعية الذي يتطلبه تصحيح الإجابات المفتو حة (Falk et al., 1999).

إن سهولة استخدام الصورة الثانية من استبيان

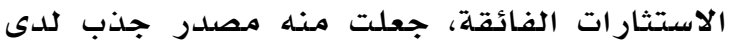
الباحثين في ميدان الموهبة، واستخخدامـه كأداة مفيدة للكشف عن الاحتياجات الاجتماعية،

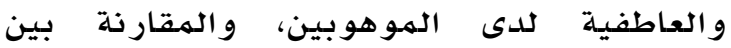

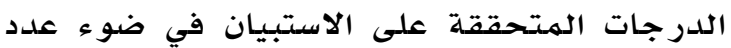

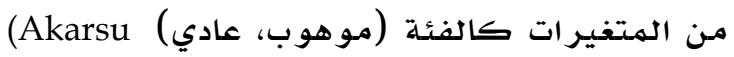
\& Guzel, 2006; Tieso, 200a; Bouchet \& Falk,

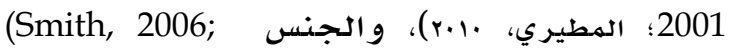
Tieso, 2007a; Tieso, 2007b; Treat, 2006; Bouchet \& Falk, 2001; Piirto, Montgomery, \& May, 2008; Al-Onaizat, 2013; Rinn, Mendaglio, Rudasill, \& McQueen, 2010; Gross et al., 2007; Miller, Falk, \& Huang, 2009; Moon \& (Gross et al., 2007; و والعهمر، Montgomery, 2005)

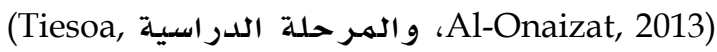

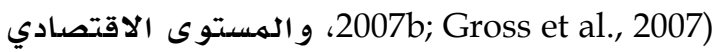
الاجتهاعي (Tieso, 2007b)، والثقافة (العنيزات و المطيري Montgomery, \& May, (2008

.(Moon \& Montgomery, 2005)

مشكلة الدراسة و أسئلتها

استحوذت المقارنة بين الاستثارات الفائقة عند

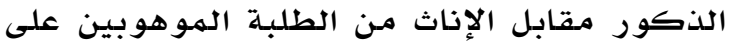

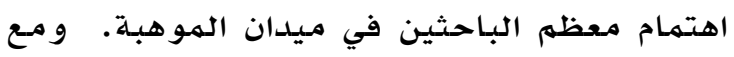
أن لهذه المقارنات ما يبررها؛ لأن فهم الظواهر 
العلاقة بين السمة موضة مورع القياس، والدرجات الهـلاحظة على الهقياس.

و بشكل عام، تمر عملية اختبار عدم التغاير بعدد

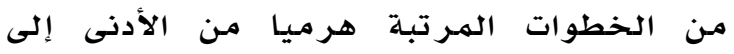
الأعلى بحيث تتفق مـ المستويات الأربعة لمفهوم عدم تغاير القياس، والمر تبـة أيضا بنفس الطريق الطويقة

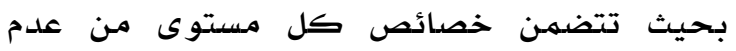
التغاير خصائص الهستوى الأدنى بالإضافة إلى

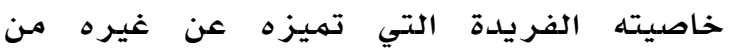
المستويات السابقة (Schmitt \& Kuljanin, 2008). و هذه الهستويات هي (Schoot, Luglig, \& Hox,

ا- عدم تغاير المكون configural invariance، و يتطلب أن يكون المعنى النظري لهكونات نموذج

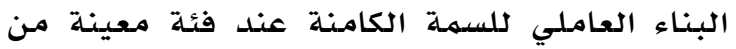
فئكات المقارنة هو نفسه عند الفئات الأخرى، بمعنى أن فئات المقارنة المختلفة تربط بين كل مـجمهوعة من الفقرات و العوامل التي تقيسها بنفس الطريقة؛ و بالمعنى الإحصائي، يتطلب هذا

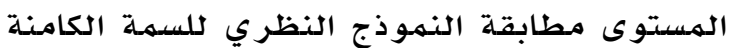

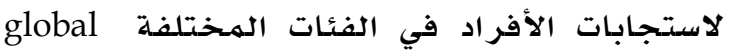

.fit

r- عدم تغاير وحدة القياس metric invariance، ويتضمن خاصيية عدم تغاير المكون في المستوى

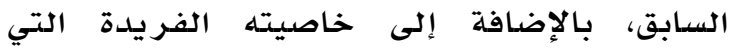
تتطلب أن يكون معنى السمـة الكامنـة عند فئلة

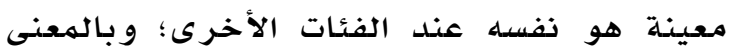
الإحصائي، يتطلب هذا المستوى تساوي تشبعات

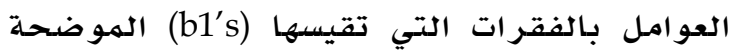
ف = b0 + b1xksi + عي معادلة الانحدار: b2xError X فقرة من فقر ات المقياس (المتغير الملاحظ). • ثابت الاذحدار b1 : تشبـع العامل أو السمـة الكامنـة بالفقرة. ksi Error
(Wu, Li, \& Zumbo, ورد في لو و لي و زمبو

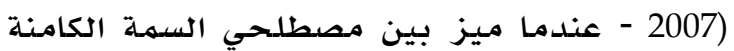
أو الدرجة الحقيقية latent trait و المفهوم construct الشائعين في تقنيات أدبيات القياس، حيث يشير إلى أن المصطلحين مختلفان؛ ففي حين تعني السمة الكامنـة أنها متغير إحصائي

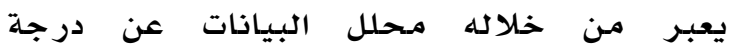
الهفحوص المتوقعة اعتمادا على استجابته

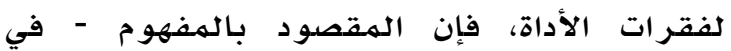
المقابل - أنه تكوين نظري مجررد يكتسب معناه من خلال علاقته بمفاهيم مجرردة أخرى ونظرية

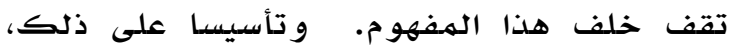
فإن صدق الأداة يتضهن الاستدلال على المفهوم من خلال استجابة الهفحوص عن فتران الهداه الأداة

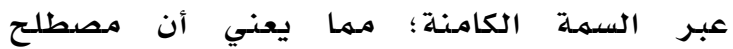

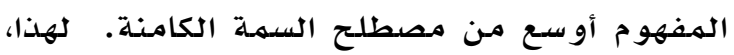
فإن الحديث عن صدق المفهوم، أو صدق البناء،

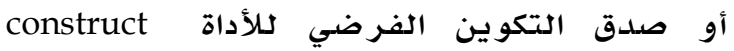
validity إمبريقية مستندة إلى مؤشرات إحصائية، و إنما

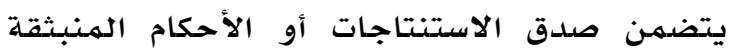
عن تلك الأدلة.

يشير دراسجو و كانفر (Drasgow \& Kanfer, (1985 إلى أن مفهوم عدم التغاير في القياس

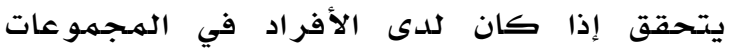

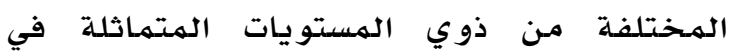

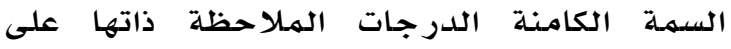
الهقياس، ويؤكدان على أن لهؤشر عدم التغاير في القياس مدلول مههم عند تفسير الفروق بين

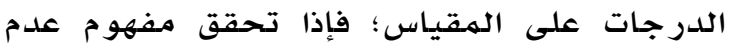

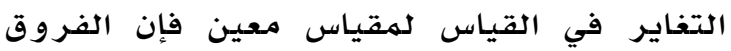

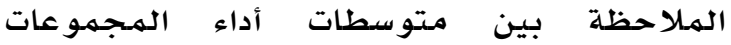

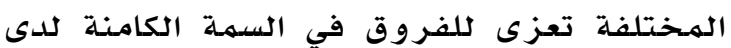
المجمموعات، في المقابل، إذا كانت العلاقة بين

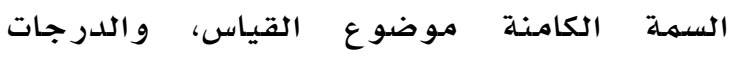

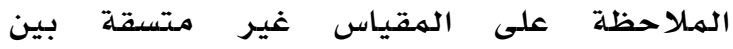

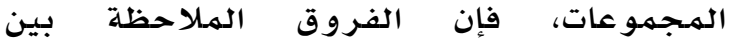

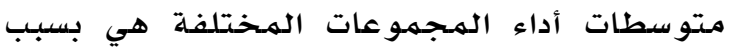
الفروق في السمـة الكامنـة، أو بسبب عدم اتساق 
الثالث من مستويات لا تغاير التدريج metric sinvariance

أهمية الدراسة

يلاحظ من خلال مراجعة الأدب السابق تعلدد

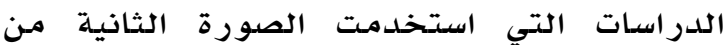
مقياس الاستثارات الفائقة OEQII خلال السنوات العشر الماضية كونه أداة فاعلة في الكشف عن الن

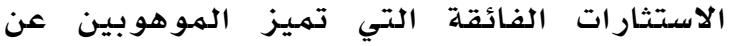

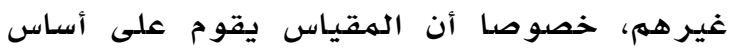
نظري له قيمته العلمية تجلى في نظرية

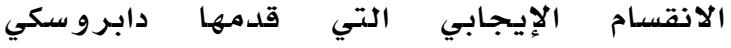

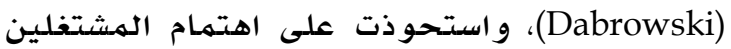
في ميدان الموهبة. ويلاحظ أيضا أن اهتمام الباحثين - سواء في البيئة الغربية، أو العربية المبه -

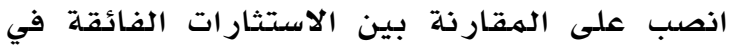
ضوء متغيرات مختتلفة كالفئة، والجنس،

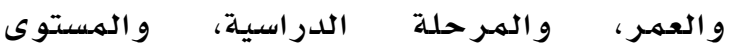
الاقتصادي الاجتهماعي، والثقافة، والتخصص...الخ

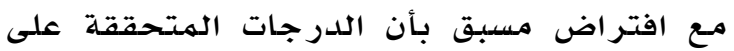

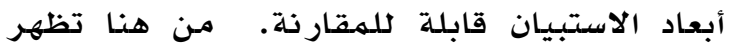
أهمية الكشف عن قابلية الدرجات المتحققة على الديلى

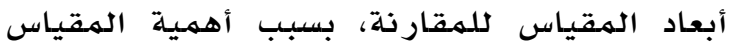

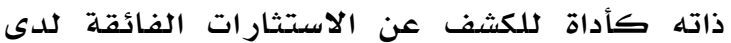
الموهوبين، وهي الهسألة التي تحظى بـاهتهام بالغ لدى العاملين في الميدان بسبب نقص أدوات

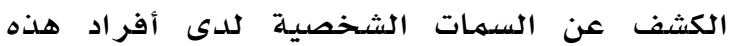

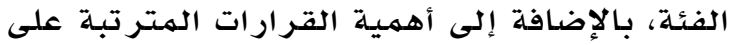

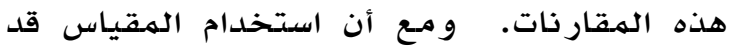

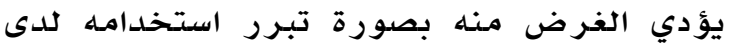
تطبيقه بصورة فردية للكشف عن الاستثارات الفائقة لدى الهوهوبين، إلا أن استخدامهه كأداة

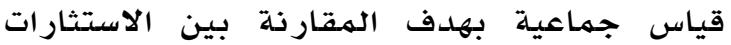

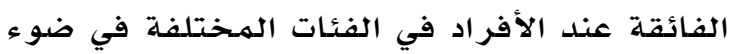
متغير معين أو أكثر يبقى موضع تساؤل، ويتطلب من الباحثين الوقوف أمامـه وتوفير

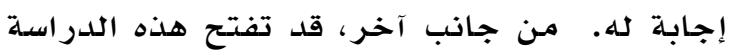
الباب أمام الباحثين في ميدان المهوهبة بشكل عام،

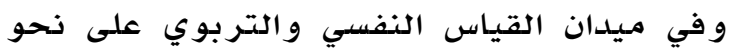
خاص، إلى إجراء دراسات مماثلة تستهدف

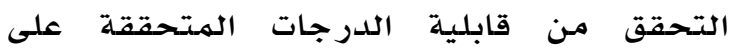

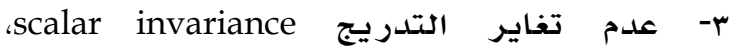
ويتضمن الخاصيتين السابقتين للمستوين

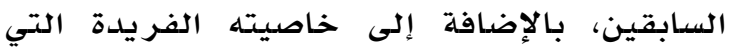
تتطلب تساوي ثوابت الانحدار (bon ) الانحدار السابقة لكل فقرة من الفقرات التي

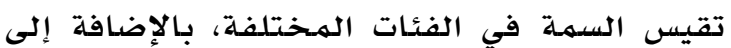
تساوي تشبعات العوامل بالفقرات التي تقيسها

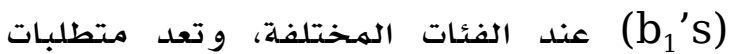
عدم تغاير التدريج scalar invariance التحد الأدنى الذي ينبغي تحققه لإجراء المقارنة بين

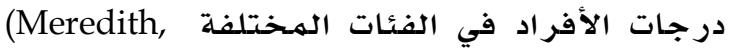

؟- عدtrict invariance عدم التغاير المطلق

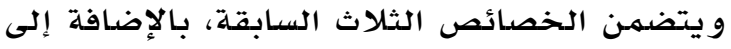
خاصيته الفريدة التي تتطلب تساوي تباينات الخطأ error variances لكل فقرة من الفقرة ات التي تقيس السمهة الكامنـة في الفئات المختلفة. بناء على ما سبق، تتلخص مشكلة الدراسة في

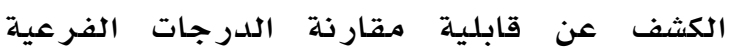
المتحققة على الأبعاد الخمسة للصورة الأردنية لمقياس الاستثارات الفائقة (Al-Onizat, 2013)

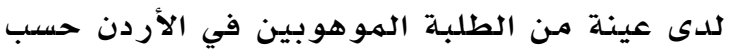
متغير الجنس، من خلال اختبار علمام تغاير

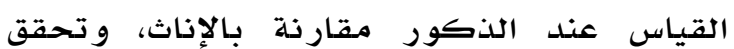
متطلبات المستوى الثالث من المستويات السابقة الذي يمثل الحد الأدنى الذي ينبغي الذيات تحققه لإجراء المقارنة بين درجات الذكور ودرجات الإناث على كل بعد من الأبعاد الخمسـة للهقياس؛

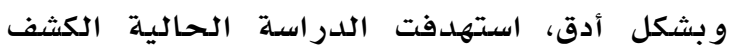
عما إذا كانت فقرات الصورة الأردنية لكل بعد الصد من أبعاد مقياس الاستثارات الفائقة تقيس السمهة ذاتها عند الذكور كمها هو الحال عند الإناث، مـما يمكن مستخدمي المقياس من مقارنة الدرجات الفر عية على أبعاد المقياس لدى الذكور والإناث

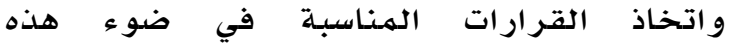

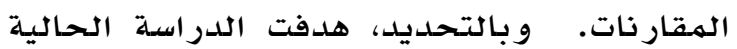

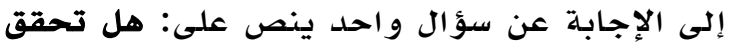

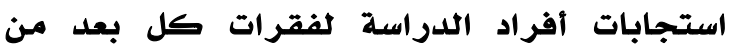
الأبعاد الخمسة للصورة الأردنية لمقياس الاستثارات الفائقة OEQII متطلبات المستوى 
في شعب صفوف التاسع والعاشر والحادي عشر

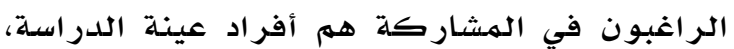

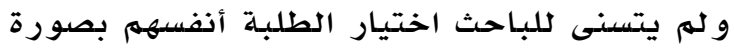

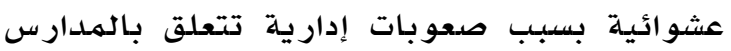
ذاتها التي شملتها الدراسـة. من ناحية ثانية، تم استخدام أداة الدراسـة (مقياس الاستثارات الفائقة OEQII إجراء أي تعديل على صياغة فقراتها، أو آلية تطبيقها و تصحيحها، وذلك لاستبعاد أي تأثير

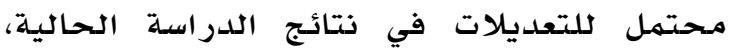

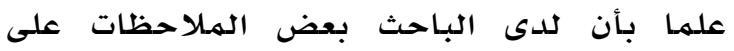
صياغة بعض الفقرات، مـع أنه تم تصويب الأخطاء المطبعية في الأداة الأصلية.

\section{مجتمع الدراسة وعينتها}

تكون مـجتمـع الدراسـة المستهدف من جميـع طلبـة

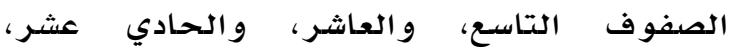
الهلتحقون بمدارس الملك عبدالله الثاني للتميز

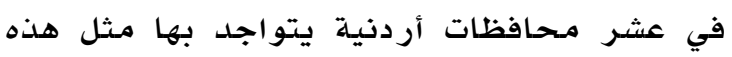

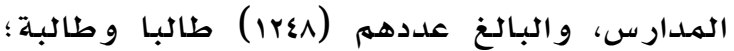

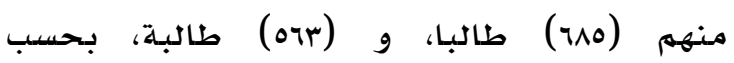
إحصائية وزارة التربية والتعليهم الأردنية للعام

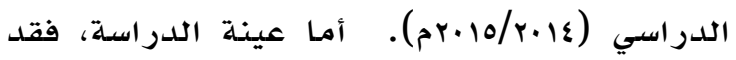
تكونت من (^§؟) طالبا و طالبـة يشكلون مـا نسبته

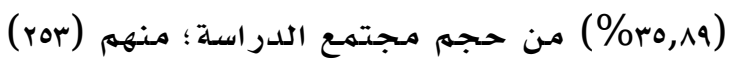
طالبا و (190) طالبة، تم اختيارهم هـ هاستخدام

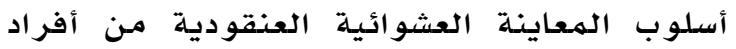

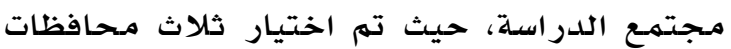
عشوائيا من بين المحافظات العشر هي محافظات احسات

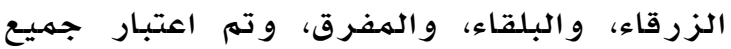
طلبة الشعب في الصفوف الثلاثة الر اغبون بالمشاركة في الدراسة هم أفراد الدراسة.

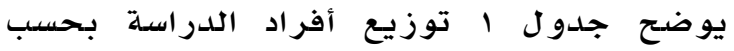
متغير ات المحافظة و الصف و الجنس.
المقاييس المختلفة للمقارنة في ضوء متغير معين أو أكثر قبل إجراء مثل هذه المقارنات.

حلدود اللدراسة ومححدداتها

يتحدد تعميم نتائج هذه الدراسلة بالهدف الذي سعت الدراسـة إلى تحقيقه، والذي اقتصر على اختبار قابلية مقارنة الدرجات الفرعية المتحققة على الصورة الأردنية لكلأبعاد الخمسـة التي

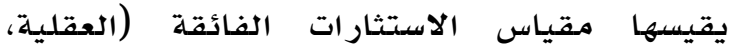
التخيلية، العاطفية، الحسية، النفس حركية النية) في ضوء متغير واحد فقط وهو متغير الجنس، و ما توفر لهذه الأداة من خصائص وسئس سيكومتريـة تبرر

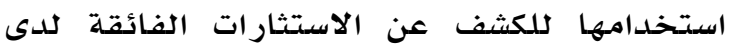

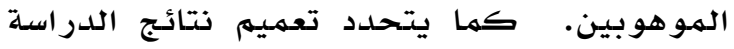

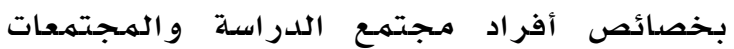
المهماثلة؛ وهم طلبـة الصفوف التاسـع و العاشر والحادي عشر الذكور و والإناث الملتحقين بمدارس المـلك عبدالله الثاني للتميز في عشر

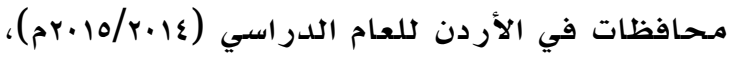
و هي الهحافظات التي يتواجد بها مثل هذه

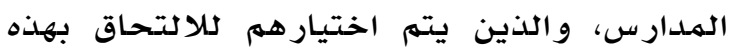

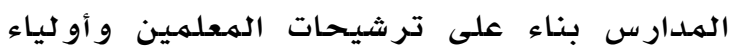
الأمور، بالإضافة إلى معيار التفوق الأكاديمي في الصفوف الثلاثة السـابقة لالتحاق، وأداءهم

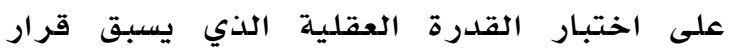

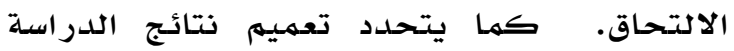
بخصائص أفرد عينة الدراسة التي اشتهلت على الى

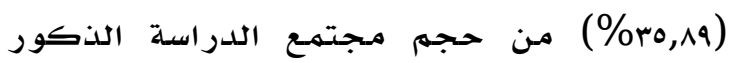

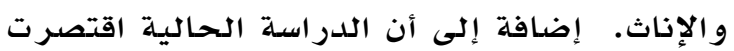

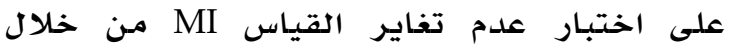

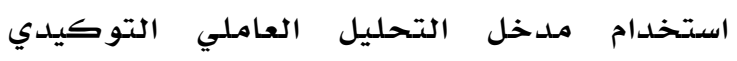
.Confirmatory Factor Analysis (CFA)

من جانب آخر، تجدر الإشارة إلى بعض الجوانب التي قد تشكل أوجه قصور محتملـة في هذه الدراسـة، والتي كانت خارجة عن قدرة الباحث

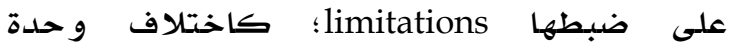
الاختيار unit of selection، عن وحلدة التحليل unit of analysis

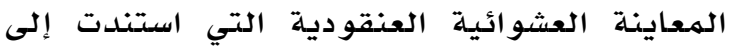

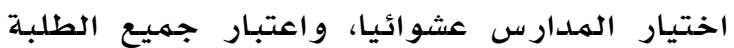


جدول 1

توزيع أفراد عينة الدراسة حسب فئات متغيرات المحافظة والصف والجنس

\begin{tabular}{|c|c|c|c|c|c|c|c|c|c|c|c|c|}
\hline \multicolumn{3}{|c|}{ الكلي } & \multicolumn{3}{|c|}{ الصف الحادي عشر } & \multicolumn{4}{|c|}{ الصف العاثر } & \multicolumn{2}{|c|}{ الصف التاسع } & \multirow{2}{*}{ المحافظة } \\
\hline مجموع & $ث$ & ذ & مجموع & $ث$ & ذ & مجموع & $ث$ & j & مجموع & $ث$ & j & \\
\hline YI $\leq$ & $\wedge \wedge$ & TYו & $1 . r$ & $\varepsilon$. & זד & 09 & r^ & T & or & $r$. & Tr & الزرقاء \\
\hline 179 & 9. & $\vee q$ & 71 & سץ & rᄉ & $\varepsilon q$ & rq & $r$. & 09 & $r \wedge$ & ا M & البلقاء \\
\hline 70 & IV & $\leq \wedge$ & -- & -- & -- & -- & -- & -- & 70 & IV & $\leqslant \wedge$ & المفرق \\
\hline$\varepsilon \varepsilon \wedge$ & 190 & ror & $17 \varepsilon$ & rr & 91 & $1 \cdot 1$ & ov & 01 & $1 V 7$ & 70 & 111 & كلي \\
\hline
\end{tabular}

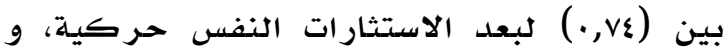

أداة الدراسة

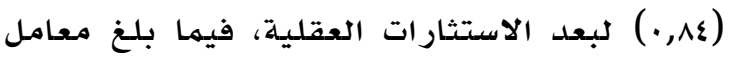
ثبات الاتساق الداخلي للمقياس ككل

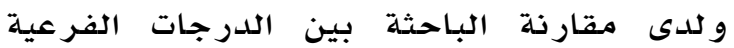
الهتحققة على كل بعد من أبعاد المقياس،

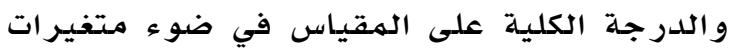

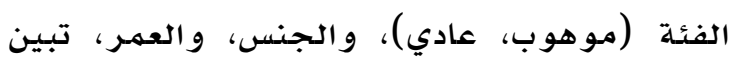

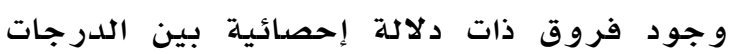

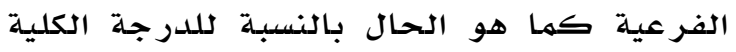
بين فئات المتغيرات الثلاثة على كافيه الأبعاد،

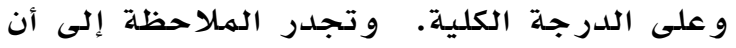

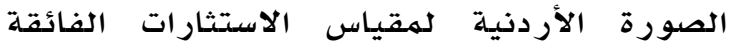

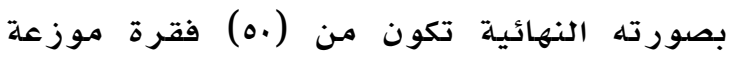

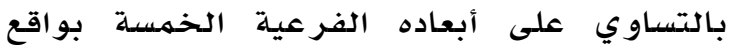
عشر فقرات في كل بعد على النحو الآتي:

بعد الاستثارات العقلية الفائقة INOE

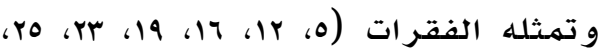
.

IMOE بعد الاستثارات التخيلية الفائقة

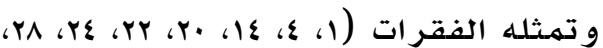

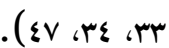

بعد الاستثار ات العاطفية الفائقة EOE

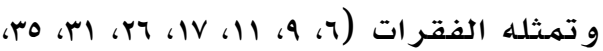
( ) ( 4 ، $\leqslant \varepsilon$ ، $)$

SOE بعد الاستثارات الحسية الفائقة

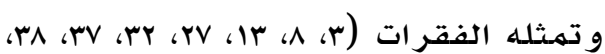
. ( «^ ، $\{7$ ، $\leqslant 0$

بعد الاستثارات النفس حركية الفائقة POE

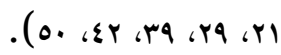

تم استخدام الصورة الأردنية لهقياس الاستثارات الفائقة OEQII (بحسب تسمية الباحثة)، و الذي قامت بترجمته من اللغة الإنجليزية إلى اللغة النه

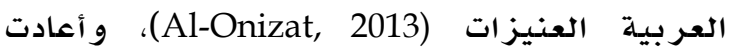
ترجمته من اللغة العربية إلى اللغة الإنجليزية للتأكد من مطابقة الترجمـة. وقامت الباحثة بتقنين المقياس واشتقاق معايير له في البيئة الأردنية، حيث اشتملت عينة التقنين الثين على (r^9)

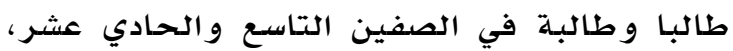

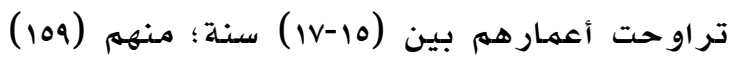

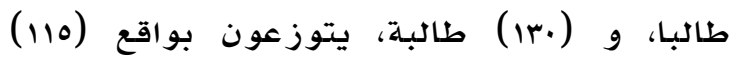

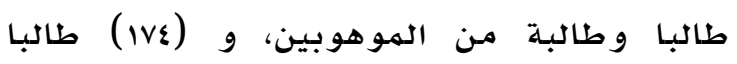

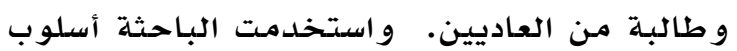

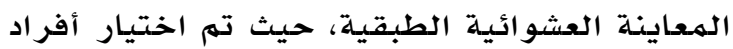

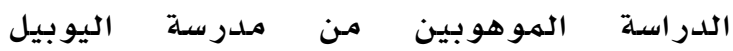
للموهوبين في العاصمة عمان، والطلبة العاديين من المدارس الحكومية في العاصمة عمان أيضدا.

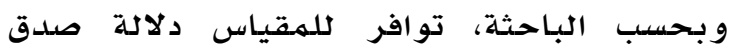

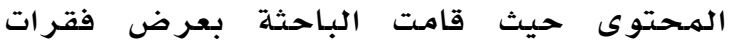
المقياس على عشرة محكمين من المهتصين في

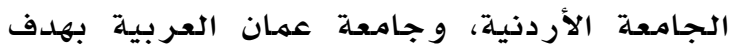

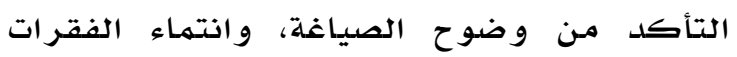

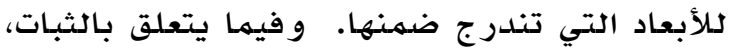

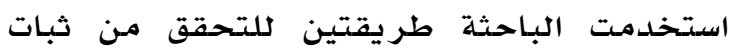

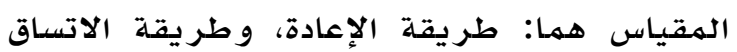

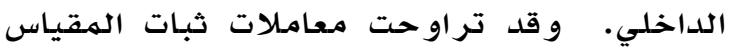

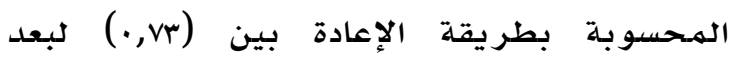

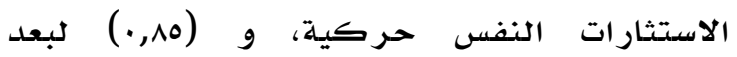

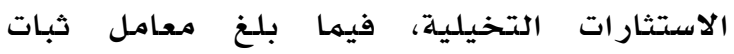
المقياس ككل المحسوب بهذه الطريقة (10,•).

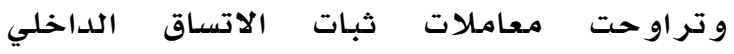

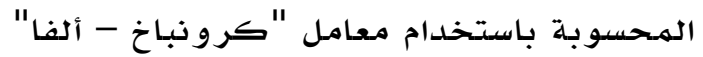


الأبعاد الخمسـة للصورة الأردنية لمقياس

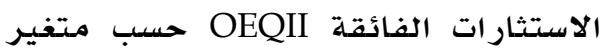

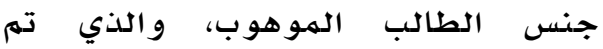

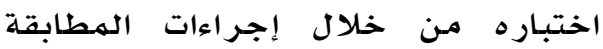

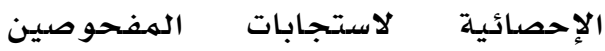
الذكور مقابل استجابات الإناث لنهموذج

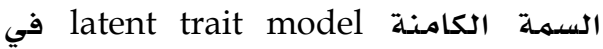
إطار نموذج العامل المشترك ك common .factor model

\section{إجر اءات الدراسة}

لأغراض تحقيق أهداف الدراسة، والإجابة عن عأهن

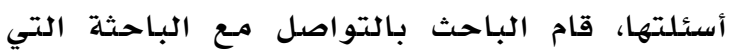
قامت بتعريب الأداة، واستئذانها لاستخدام الأداة

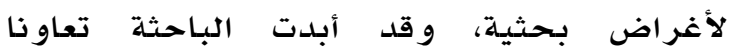
ملحوظا؛ حيث وفرت كل ما يتعلق بالأداة

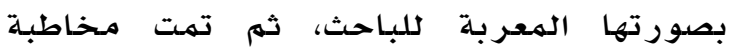
وزارة التربية والتعليهم للسهماح للباحث بتطبيق التيق أداة الدراسـة على طلبـة الصفوف التاسـع، و العاشر ،

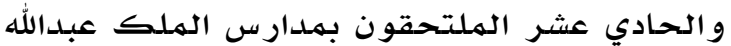
الثاني للتهيز في الأردن، بعد ذلك قام الباحث

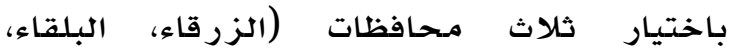
المفرق) - بصورة عشوائية - من المحافظات العشر التي يتواجد بها مثل هذه المدارس في

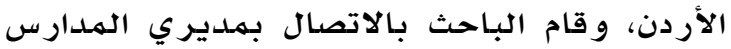
في المحافظات الثلاث المستهدفة بهدف ترتيب مواعيد زيارات هذه المدارس، وذلك في نهاية

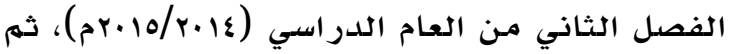

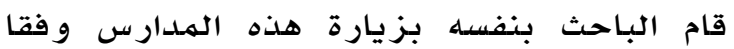
للمهو اعيد المـحددة، والتقى بالطلبـة في شعب كل

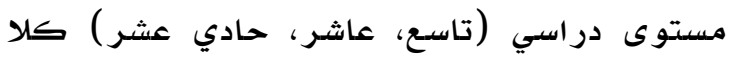
على حده في الغرف الصفية تحت إشراف أحس أحد

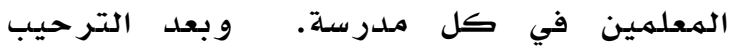

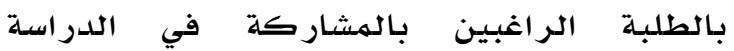
و شكر هم على تعاو نهم، قدم الباحث شرحا موجزا لأهداف الدراسة مبرزا أهمية الجدية في الإجابة عن فقرات الهقياس الأمر الذي ينعكس على دقة

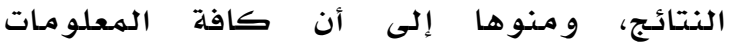

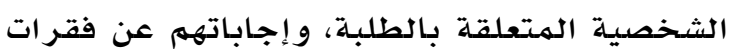
المقياس ستحاط بكامل السرية، ولن تستخدل
و تجلدر الإثارة أيضا إلى أن الباحث الحالي

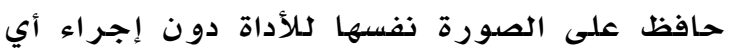
تغيير على صياغة فقراتها، أو آلية تطبيقها

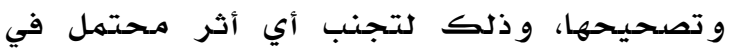
نتائج الدر اسلة الحالية. التعريفات الإجرائية للمصطلحات

تم استخخدام بعض المصطلحات في الدراسـة الحالية مها يقتضي تعريفها إجرائيا في سياق هذه الدراسـة، ووهي على النحو الآتي:

قابلية الهقارنة: هي إمكانية مقارنة

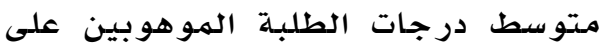

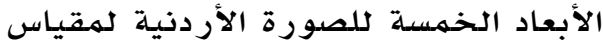
الاستثار ات الفائقة OEQII حسب متغير جنس الطالب.

الطلبـة الموهوبين: همر الطلبـة المسجلين في الصفوف التاسع، و العاشر، و والحادي عشر في مدارس الملك عبدالله الثاني

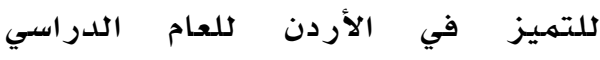
. $(r+10 / r+1 \varepsilon)$

الاستثار ات الفائقة: هي الشدة الهتطرفة،

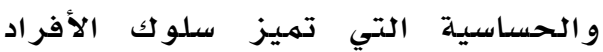
الهوهوبين عن غير هم من الأفراد العاديين، ويعبر عنها بدرجات أفر اد عينة

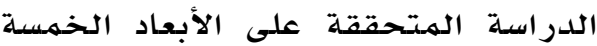

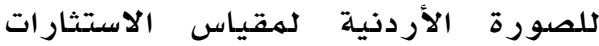
الفائقة OEQII.

عدم تغاير القياس MI: عدم تأثر المقياس بأية خاصية تلعلق بالأفراد الهفحوصين، أو أي أثر محتمل ناتج عن السياق الذي تتم فيه عملية القياس، وتأثره فقط بالسهمة التي يقيسها. ويمكن تعريفه أيضا بأنه عدم تحيز المقياس لأبي فئة من فئات المفحوصين على حساب الفئات الأخرى. و في سياق الدرراسة الحالية، يمكن تعريف مفهوم عدم تغاير القياس بأنه متطلب سابق ينبغي توافره في المقياس قبل المقارنة

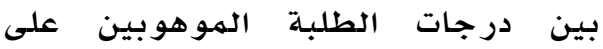


الذكور، فقد تبين وجود ثمان فقرات تقل قيمها

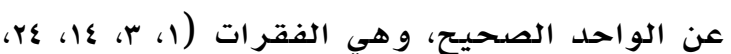

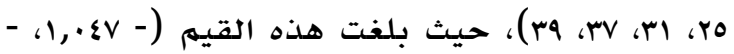

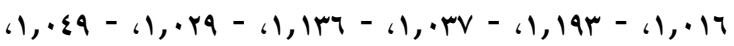

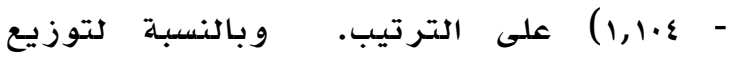
استجابات الإناث، فقد تبين وجود أربع فئر الترات

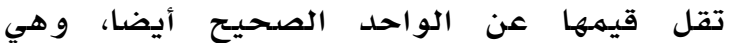

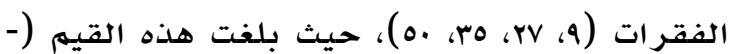

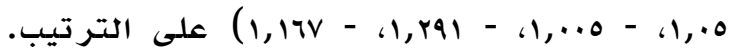
ووفيما تبين عدم وجود أي فقرة من الفقرات تتقمص أي نوع من نوعي الالتواء الموجب أو أو أونات السالب بشكل متطرف في كلا الفئتين، أشارت النتائج إلى وجود فقرات مختلفة في الفئتين تتقهص نوعا من التفلطح، لكن الأمر يبقى

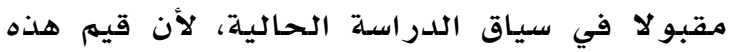

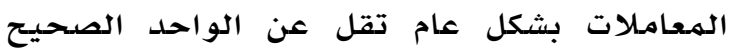

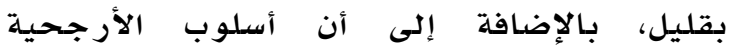
القصوى ML المستخدم في الدراسلة الداسلة الحالية لتقدير مؤشرات عدم التغاير في سياق التحليل

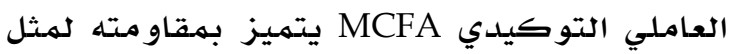

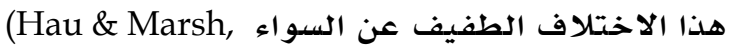
.2004)

في المقابل، يمكن القول أن الأمر يقتضي إعادة

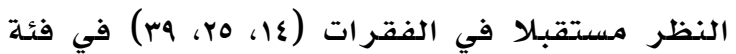

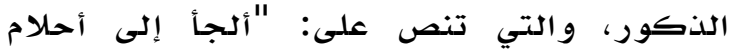

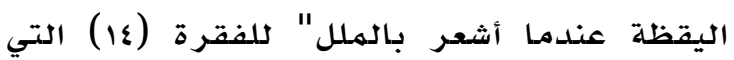

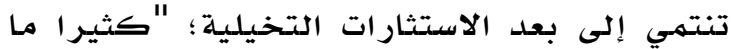

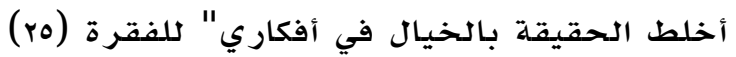

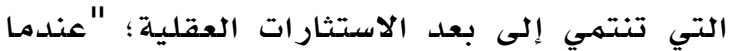

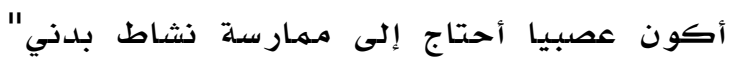

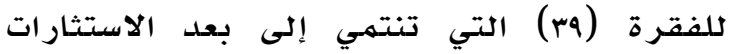
النفس حركية. أما في فئة الإناث، فربما تحتاج التهاج

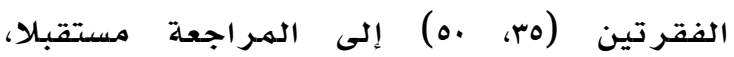

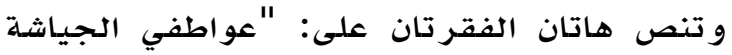

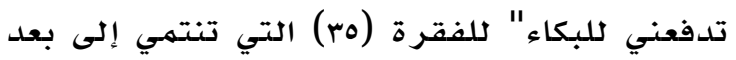

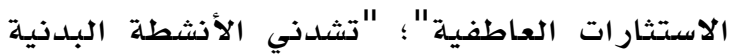

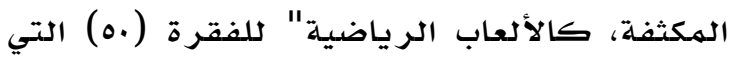

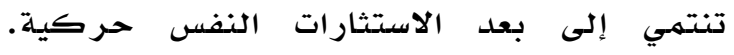

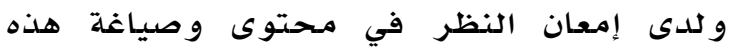

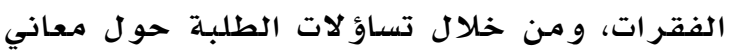

لأغراض البحث العلمي فقط، كما وجه الباحث

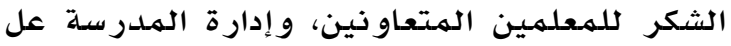

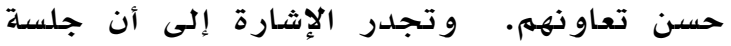
التطبيق الواحدة استغرقت حوالي (.r) دقيقة.

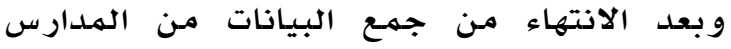

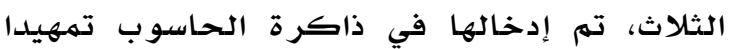
لتحليلها. أساليب تحليل البيانات تم حساب قيم معاملات الالتواء، و التفلطح لاستجابات أفراد كل فئة من فئتي عينة

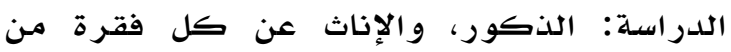

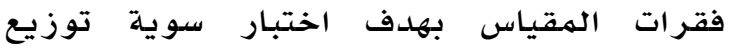
الاستجابات، والتأكد من عدم وجود مشاهدات

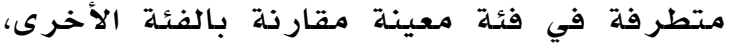
وذلك قبل إخضاع البيانات لأسلوب التحليل

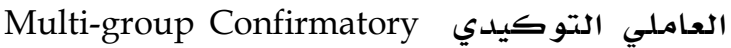
Factor Analysis (MCFA) التشبعات على العوامل، وثابت الانحدار، و تباين

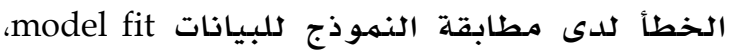

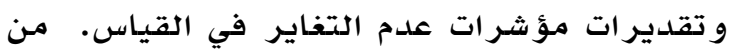
جهة ثانية، تم استخدام طريقة الأرجحية القصوى Maximum Likelihood (ML) لتقدير

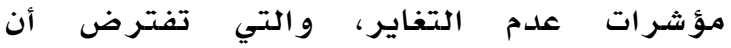

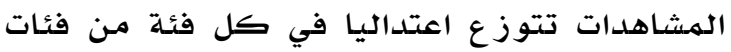

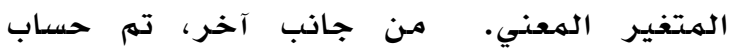

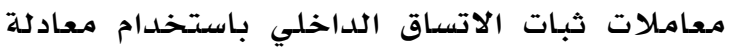

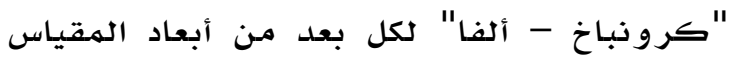

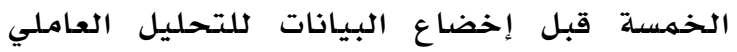
التوكيدي بهدف التأكد من ثبات الأداة.

\section{نتائج الدر اسة ومناقشتها}

قبل إخضاع البيانات لأسلوب التحليل العاملي

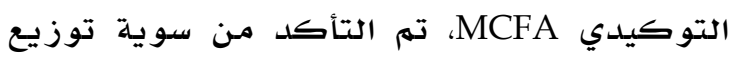
البيانات من خلال حساب قيم معاملات الالتواء

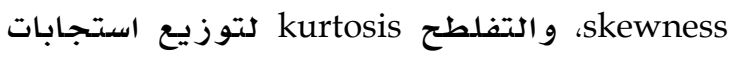
الذكور والإناث كلا على حده، وذلك عن كل فقرة من فقرات المقياس. وقد أشارت النتائج

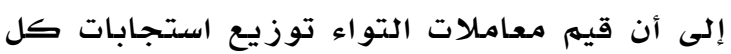

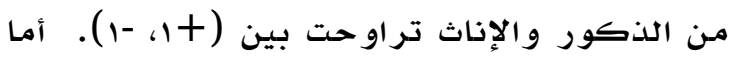

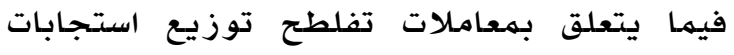


INOE

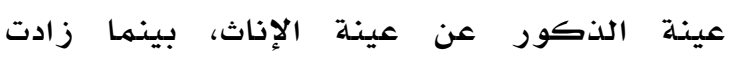

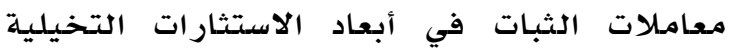

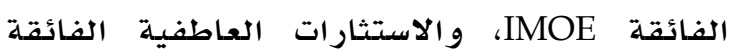

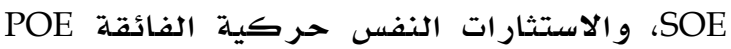
في عينة الإناث عن عينـة الذكور، وقولد تراوحت الفروق بين معاملات الثبات المحسوبة بهية لكل بعد من أبعاد المقياس الخمسـة و لكل مـن الذكور

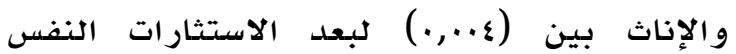

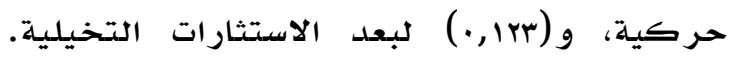
وبصرف النظر عن الفروق بين معامـلات الثبات الهحسوبة في كل من عينتي الذكور والإناث، يمكن القول بأن جميع معاملات الثبات في كلتهات

العينتين تعدل مقبو لة لأغر اض الدر اسـة الحالية. مـن جانب آخر، تم حساب المتوسطات الحسابية

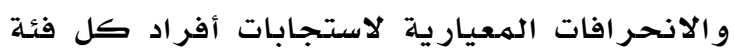

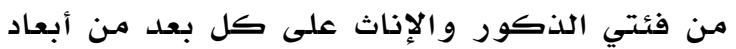
الصورة الأردنية لمقياس الاستثارات الفائقل OEQII المستقللة

يتضح من جدول م أن متوسطات درجات الذكور تختلف عن متوسطات درجات الإناث على جميع أبعاد الصورة الأردنية لمقياس الاستثارات الفائقة OEQII. و ولدى الكشف عن دلالة الفروق بين هذه المتوسطات، فقد كشفت نتائج اختبار

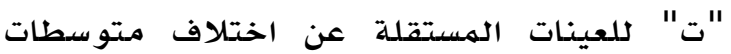
درجات الذكور مقارنة بمتوسطات درجات الإناث في بعلدي الاستثارات العاطفية الفائقة pOE (10.05 لصالح الإناث، والاستثارات النفس حركية

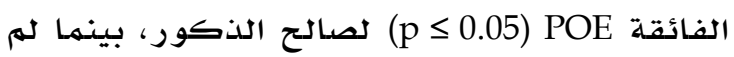
يتبين وجود فروق معنوية ذات دلالة إحصدائية

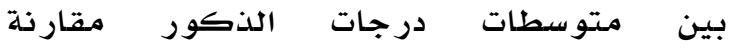
بمتوسطات درجات الإناث على ثلاثة أبعاد للمقياس هي: الاستثارات العقلية الفائقة INOE، لهاتِ

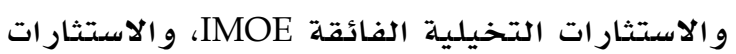

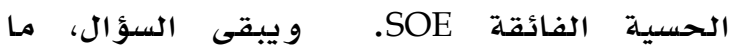
مشروعية مقار نة هذه المتوسطات إن لهم يتو افر لأبعاد المقياس مؤشرات عن عدم تغاير القياس ماسه

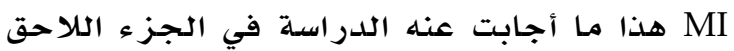

بعض المصطلحات أثناء عملية جمـع الباحث للبيانات كمصطلح "الجياشة" الوارد في الفقرة

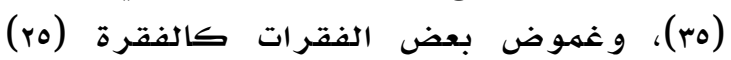

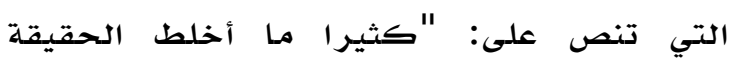

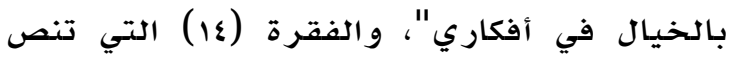

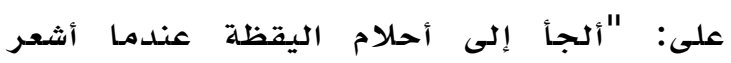
بالملل" ربما ربما كان السبب وراء زيادة التباين بين

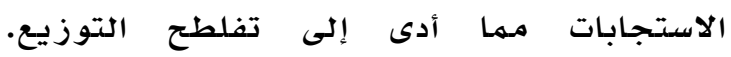

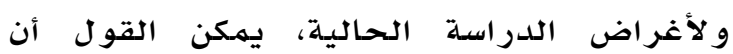

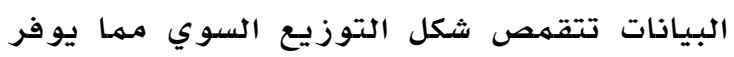

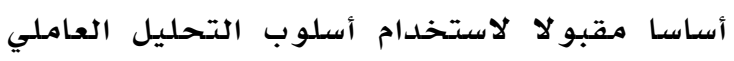
التوكيدي MCFA بهدف الكثف عن مؤشرات عدم التغاير في القياس.

من جانب ثان، تم التحقق من ثبات الاتساق الداخلي لكل بعد مـ أبعاد الأداة قبل إخضاع

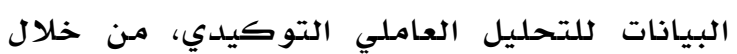

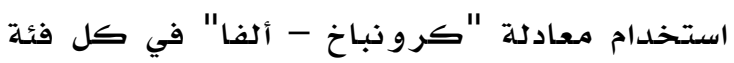
من فئتي الذكور والإناث كما هو موضـح في

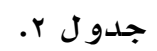

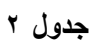

معاملات ثبات الاتساق الداخلي (كرونباخ - ألفا) لكل بعد من أبعاد

\begin{tabular}{|c|c|c|}
\hline \multicolumn{3}{|c|}{ الأداة ولكل فئة من الجنسين } \\
\hline $\begin{aligned} \text { الإناث (190 } & \text { (190 }\end{aligned}$ & $\begin{array}{l}\text { الذكور (ن = ror } \\
\text { (ن) }\end{array}$ & 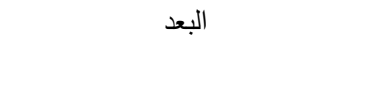 \\
\hline$\cdot, \vee \vee 70$ & $\cdot, \Lambda T \cdot$ & الاستتارات العقلية الفائقة INOE \\
\hline$\cdot, \wedge 11$ & $\cdot, \uparrow \wedge \Lambda$ & الاسنتارات التخيلية الفائقة IMOE \\
\hline$\cdot, \mathrm{VAV}$ & $\cdot, T \vee \wedge$ & الاستثارات العاطفية الفائقة EOE \\
\hline$\cdot, 79$. & $\cdot, \times 10$ & الاستثارات الحسية الفائقة SOE \\
\hline$\cdot, \wedge r q$ & $\cdot, \lambda r_{0}$ & الاستثثارات النفس حركية الفائقة POE \\
\hline
\end{tabular}

يتضح من جدول r أن معامـلات الثبات المحسدوبة

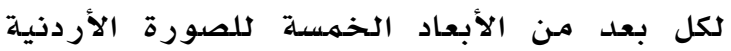
لمقياس الاستثارات الفائقة في كل من عينتي

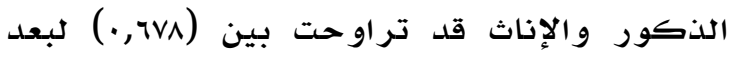

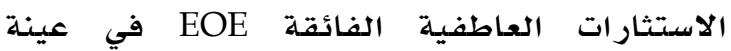

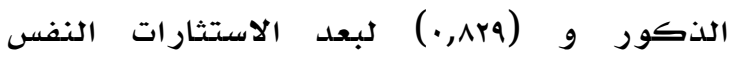
حركية الفائقة POE في عينة الإناث. و ويلاحظ

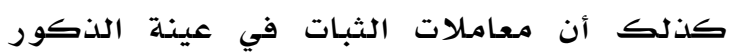
اختلفت عن عينة الإناث؛ حيث زادت معاملات الات ميات الثبات في بعدي الاستثارات العقلية الفائقة 
الاستثارات الحسية SOE، الاستثارات النفس حركية POE)، والتي يتشبع كل منها بعشر التر

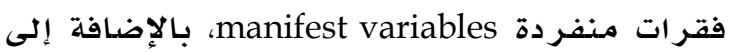
تباين الخطأ لكل فقرة، وذلك من خلال توظيف بر مجية AMOS-20 (انظر الشكل ا الذي اهني يمثل

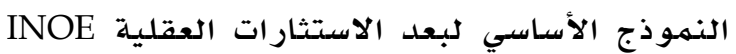
كمثال توضيحي، علما بأنه تمت مطابقة النهموذج ادهي

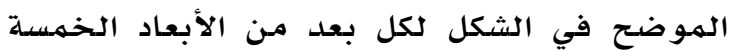
على حده).

و تم استخدام ثلاثة مؤشر ات للمطابقة هي: مربع

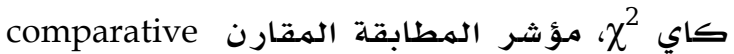
fit index (CFI)

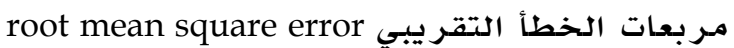
approximation (RMSEA) ع. كما تم استخدام مؤشرات القطع الآتية للحكمى على درجة مطابقة النهوذج للبيانات :(Kline, 2010)
لدى إخضاع البيانات لأسلوب التحليل العاملي التوكيدي للمجموعات المتعددة MCFA،

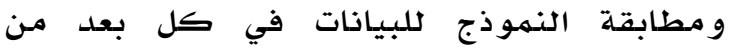
الأبعاد الخمسـة للمقياس في إطار نموذج العامل المشترك common factor model.

للإجابة عن سؤال الدراسة: "هل تحقق استجابات

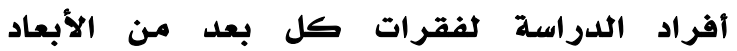
الخمسة للصورة الأردنية لمقياس الاستثارات الفائقة OEQII متطلبات مستوى عدم تغاير التدريج metric invariance وهو المستوى الثالث من مستويات عدم تغاير القياسع"، تم تحديد النهموذج الأسساسي baseline model في الخطوة الأولى، ثم تمت مطابقة هذا النموذج لاستجابات كل مـن الذكور والإناث على حده لفقرات كل

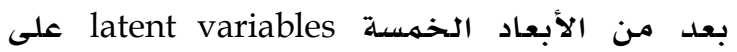

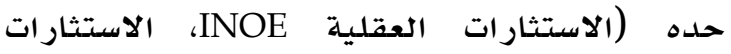

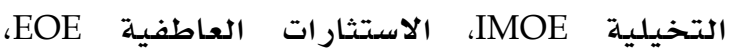

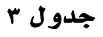

المتوسطات الحسابية (م) والانحرافات المعيارية (ع) لدرجات أفراد الدراسة على كل بعد من الأبعاد الفرعية للمقياس، ونتائج اختبار "ت

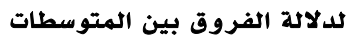

\begin{tabular}{|c|c|c|c|c|c|c|c|c|}
\hline \multirow{2}{*}{$\mathrm{D}$} & \multirow{2}{*}{ مستوى الدلايلة } & \multirow{2}{*}{ - ح.د } & \multirow{2}{*}{ ت } & \multicolumn{2}{|c|}{ إناث (ن = 1900) } & \multicolumn{2}{|c|}{ ذكور (ن = ror) } & \multirow{2}{*}{ البعد البد } \\
\hline & & & & $\varepsilon$ & p & $\varepsilon$ & r & \\
\hline •,OY &., $0 \vee \wedge$ & $\leqslant \leqslant 7$ & $\cdot, 00 \mathrm{~V}$ & $\cdot, T / Y$ & $r, v \cdot v$ & $\cdot, V Y I$ & r, roo & العقلية INOE \\
\hline$\cdot, 11 \leqslant$ & $\cdot, \Gamma \wedge \varepsilon$ & $\varepsilon \leqslant 7$ & $\cdot, \wedge \vee Y$ & $\cdot, \times 19$ & r,人тo & • & r.vq. & التخيلية IMOE \\
\hline א זrז, • & $\cdot, \cdots q$ & $\varepsilon \leqslant 7$ & $r, T) V$ & צד & וזיזי & שדז, & $r, 1.7$ & العاطفية EOE \\
\hline ., & $\cdot, \vee \vee १ ९$ & $\varepsilon \leqslant 7$ & $\cdot, r 00$ &., 094 & ס & ror, & r,r. & SOE الحسية \\
\hline • & $\cdot, \cdot 1 \pi$ & $\leq \leqslant 7$ & $r, 01 \leq$ & $\cdot, \times 10$ & 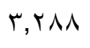 & $\cdot, \times 10$ & r,or. & النفس حركية POE \\
\hline
\end{tabular}

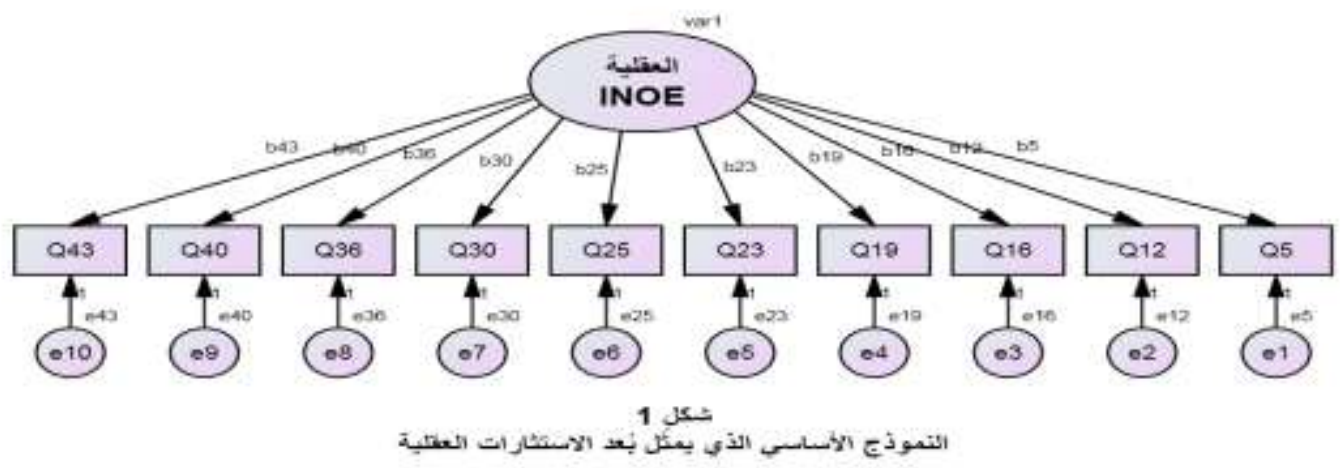




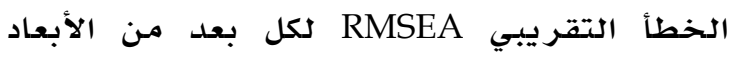

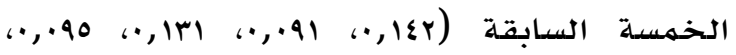

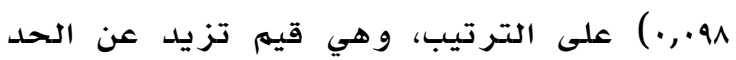

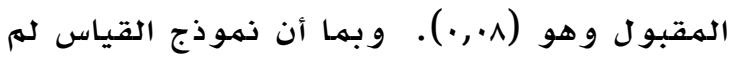

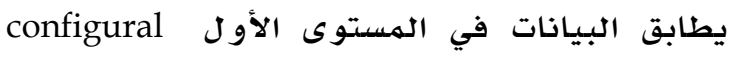
من مستويات عدم تغ تغاير القياس

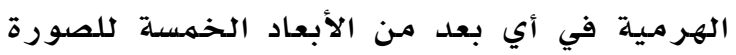

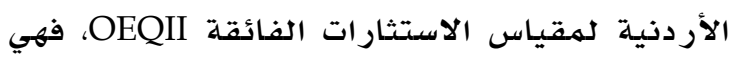

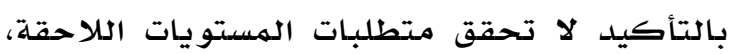

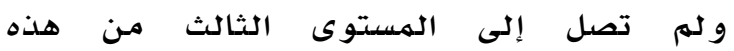
المستويات وهو مستوى عدم تغاير التدريج scalar invariance

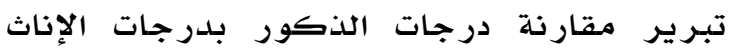

الهتحققة على هذه الأبعاد (Meredith, 1993). كشفت نتائج الدراسلة الحالية عن عدم قابلية

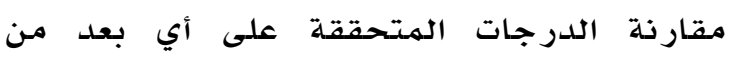

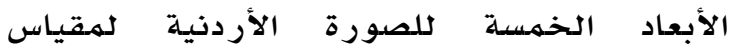
الاستثار ات الفائقة حسب متغير الجنس، مها يعني الدي الدئ

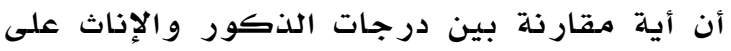

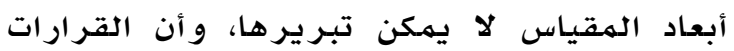

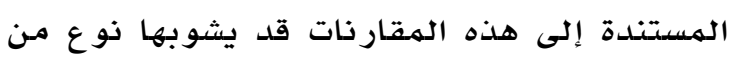

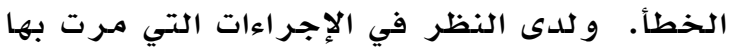
عملية تطوير الصورة الأردنية للمقياس، يتبين

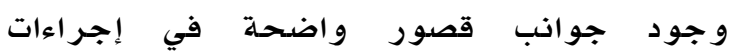

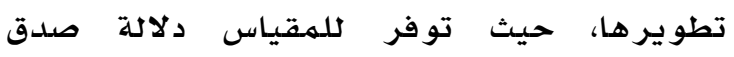

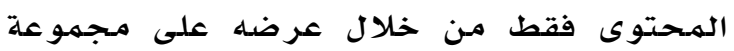

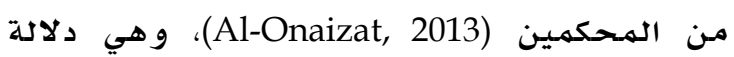
صدق غير كافية من من الناحية السيكومترية،

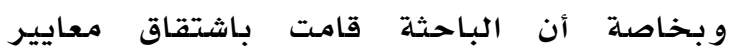

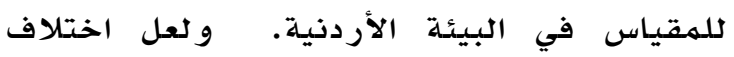

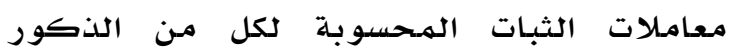
و الإناث على حده على بعدي الاستثار ات التخيلية

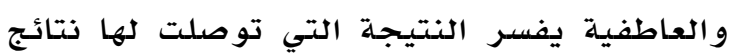
الدر اسـة الحالية.

بعيدا عن مسألة قابلية المقارنة بين الدرجات على أبعاد المقياس حسب متتغير الجنس، فقد

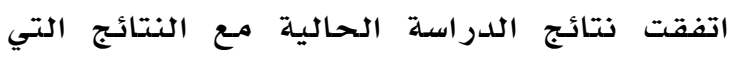

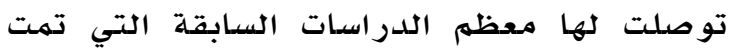

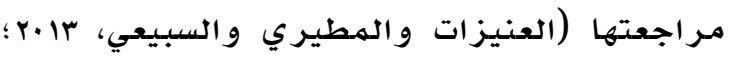
;Tieso, ;Miller et al., 2009 ;Gross et al., 2007
يعد النهوذج مطابقا للبيانات إذا تساوت

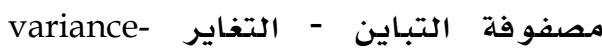
covariance matrix الذكور والإناث، والتي يدل عليها الإحصائي مر بـع كاي الإناث

يعد النموذذج مطابقا للبيانات بشكل كاف

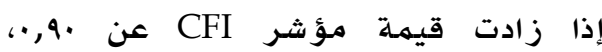
و تكون المطابقة أفضل إذا زادت قيمتهـ عن 90

يعد النموذج مطابقا للبيانات إذا قلت

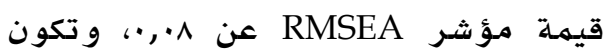

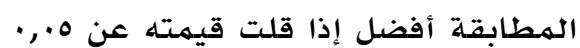

جدول ؛

مؤشرات مطابقة النموذج للبيانات في كل بعد من الأبعاد الخمسة

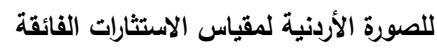

\begin{tabular}{|c|c|c|c|c|}
\hline RMSEA & CFI & df & $\chi^{2}$ & البعد \\
\hline$\cdot, 1 \leq r$ & $\cdot, V Y$. & $v$. & $0 T \Sigma, 11 Y$ & العقلية INOE \\
\hline$\cdot, .91$ & $\cdot, \mathrm{VVT}$ & $v$. & $01 Y, Y 19$ & التخيليةIMOE \\
\hline |T|, & $\cdot, 719$ & $v \cdot$ & $\varepsilon \vee q, \Gamma Y \leqslant$ & العاطفية EOE \\
\hline$\cdot, .90$ & אזT, & $v$. & $r \leqslant Y, V \circ T$ & SOE الحسية \\
\hline$\cdot, .91$ & •, TYA & $v$. & $\varepsilon া \pi, \tau \pi \varepsilon$ & النفس حركية \\
\hline
\end{tabular}

أشارت النتائج الموضحة في جدول ع إلى عدم الدماء

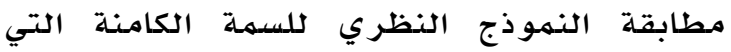

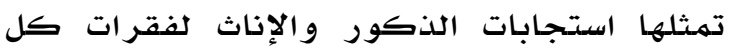
بعد من الأبعاد الخمسة للصورة الأردنية لمقياس الاستثار ات الفائقة OEQII ؛ مـما يعني عدم تحقيق متطلب المستوى الأول من مستويات عدم تغاير القياس configural invariance وهو مد مدم تغاير المكون، حيث بلغت قيم مربع كاي الحئ في الأبعاد

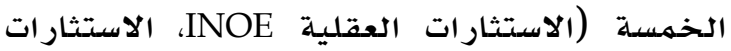

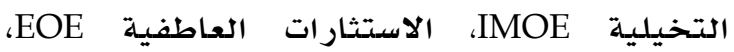

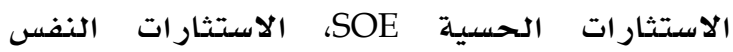

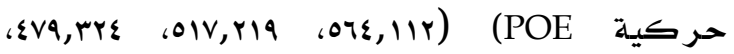
مة A مؤشر المطابقة المقارن CFI لكل بعد من الأبعاد

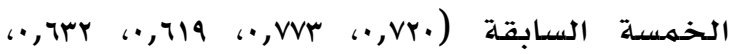

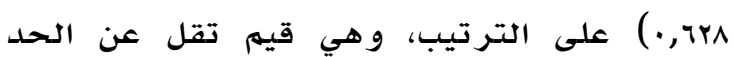

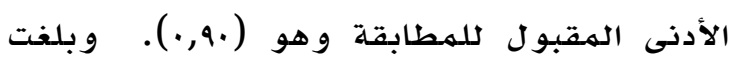

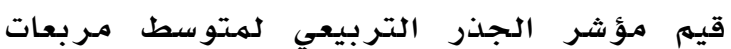


دولة الكويت، و نظرائهم الطلبة الهموهوبين في الأردن، علما بأنه تم جمع البه البيانات في الأردن

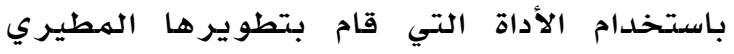

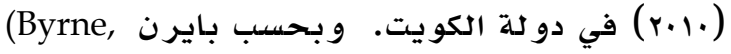

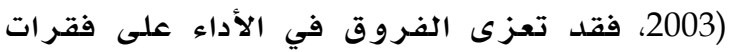

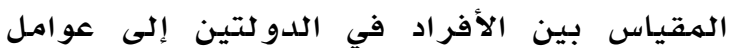

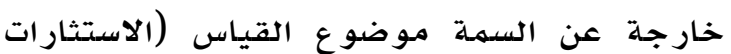
الفائقة)، حيث يمكن أن يكون مفهوم الاستثارات

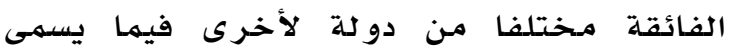
بتحيز الهفهوم construct bias.

ينبغي التنويه إلى أن تفسير نتائج الدراسـة

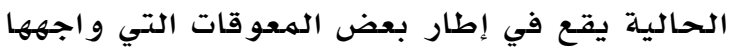

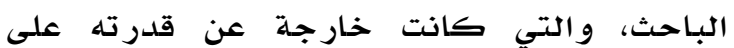
ضبطها؛ كاختلاف وحدة الاختيار عن وحدة التحليل. هذا بالإضافة إلى استخدام الباحث للصورة الأردنية لهقياس الاستثارات الفائقة دون إجراء أي تعديل على صياغة فقراتها، و تعليهات الإجابة، و آلية التطبيق، والتصحيح خشية تأثر

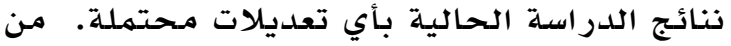
ناحية ثانية، يتحلدد تعميم ذنتائج الدراسة اسلة الحالية في إطار متغير الجنس فقط، وهذا يستدعي

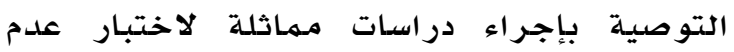
تغاير القياس IM في إطار متغير ات تصنيفية

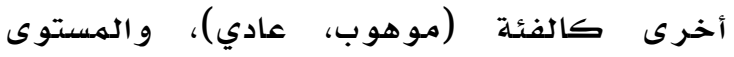

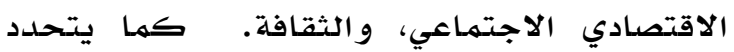

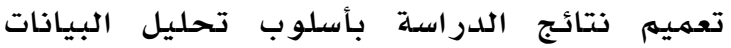

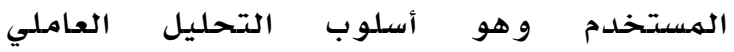
التوكيدي CFA و الذي يقع في إطار النظرية التقليدية في القياس، مها ليستدعي التوصيلة

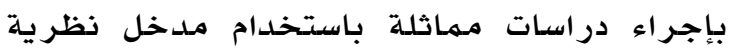
الاستجابة للفقرة Item Response Theory (IRT) و الكثف عن الأداء التفاضلي للفقرة Item Differential Functioning (IDF)

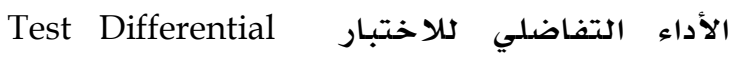
.Functioning (TDF)

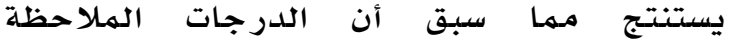

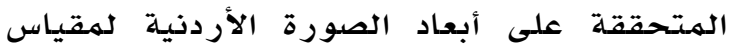

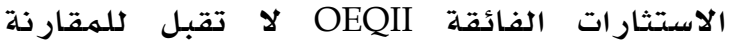

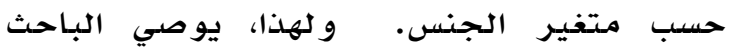

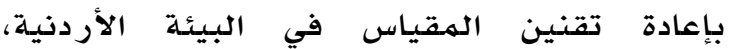

;Piirto et al., ;Smith, 2006 Teiso, ;2007b 2007a Moon \& ; Boucher \& Falk, 20012008 (Montgomery, 2005 متوسطي أداء الذكور والإناث على بعد

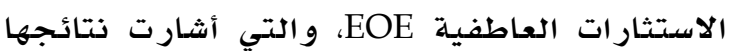
إلى أن الإناث يحققن درجات أعلى من الذهور

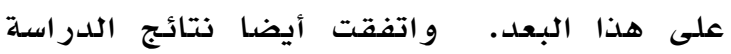
الحالية مـع نتائج عدد قليل مـن الدراسـات السابقة

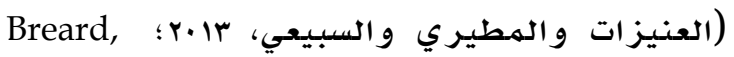

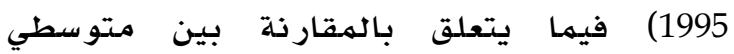
استجابات الذكور والإناث على بعد الاستثارات النفس حركية POE، والتي بينت أن الذكور يحققون درجات أعلى من الإناث على هذا البعد. و في الوقت نفسه، اختلفت نتائج الدراسلة الحالية

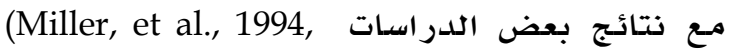
التي أثارت نتائجها إلى أن الإناث Tieso, 2007a)

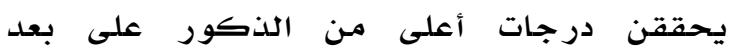

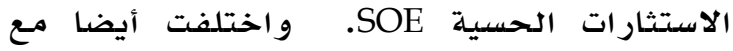

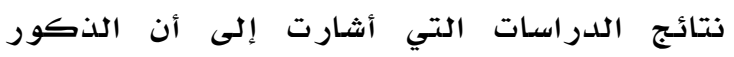

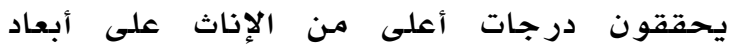

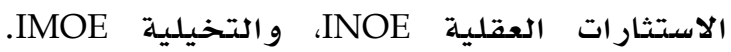

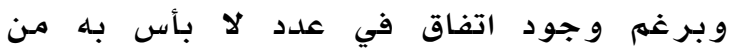

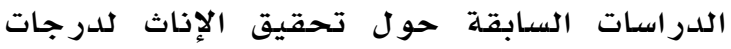
أعلى من الذكور على بعد الاستثارات العاطفية الذاتية EOE في نتائج الدراسات السابقة حول أبعاد الهقياس

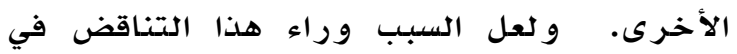
النتائج يعود إلى عدم مطابقة نموذج العامل

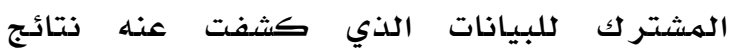
الدر اسـة الدحالية.

مـع أن إجراء المقارنات بين درجات الموهوبين على أبعاد المقياس في ضوء متغير ات تصنيفية

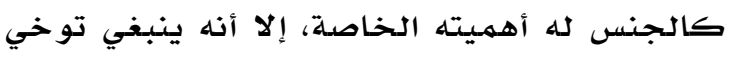

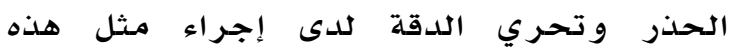
الهقارنات بسبب عدم توافر مؤشرات حول عدم إم الفرات

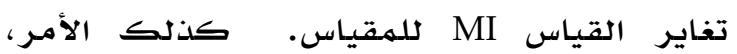
ينبغي توخي الحذر لدى استخدام المقياس في

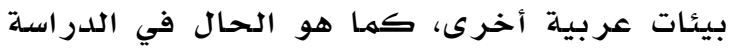
عبر الثقافية التي أجرتها العنيزات و الهطيري

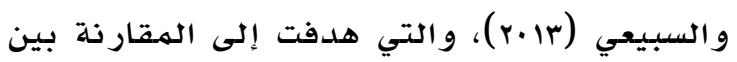

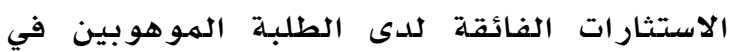


developmental potential of young gifted children. In S. Daniels, \& M. M.

Piechowski (Eds.), Living with intensity (pp. 33-56). USA: Great Potential Press, Inc.

Daniels, S., \& Piechowski, M. M. (2009a). Embracing Intensity: Overexcitability, Sensitivity and the developmental potential of the gifted. In S. Daniels, \& M. M. Piechoeski (Eds.), Living with intensity (pp. 3-17). USA: Great Potential Press, Inc.

Daniels, S., \& Piechowski, M. M. (2009b). Dabrowski's levels and the process of development. In S. Daniels, \& M. M. Piechoeski (Eds.), Living with intensity (pp. 19-29). USA: Great Potential Press, Inc.

Drasgow, F., \& Kanfer, R. (1985). Equivalence of psychological measurement in heterogeneous populations. Journal of Applied Psychology, 70(4), 662.

Falk, R. F., Lind, S., Miller, N. B., Piechowski, M. M., \& Silverman, L. K. (1999). The overexcitability questionnaire-two (OEQII). Denver, CO: Institute for the Study of Advanced Development.

Gross, C. M., Rinn, A. N., \& Jamieson, K. M. (2007). Gifted adolescents' overexcitabilities and self-concepts: An analysis of gender level. Roeper Review 8, 115-119.

Hau, K. \& Marsh, H. (2004). The use of item parcels in structural equation modeling: Non-normal data and small sample sizes. British Journal of Mathematical and Statistical Psychology, 57, 327-351.

Kline, R. B. (2010). Principles and practice of structural equation modeling ( $3^{\text {rd }}$ ed.). New York, NY: Guilford Press.

Meredith, W. (1993). Measurement invariance, factor analysis and factorial invariance. Psychometrika, 58, 525-453.

Miller, N. B., Falk, R. F., \& Huang, Y. (2009). Gender identity and the overexcitability profiles of gifted students. Roeper Review, 31, 161-169.

Miller, N. B., Silverman, L., \& Falk, R.F. (1994). Emotional development, intellectual ability, and gender. Journal for the Education of the Gifted, 18(1), 20-38.
Moon, J. H., \& Montgomery, D. (2005). Profiles of overexcitabilities for Korean high school gifted students according to gender and domain of study. Journal of Gifted/Talented Education, 15, 1-10.

Piechowski, M. M., \& Calangelo, N. (1984). Developmental potential of the gifted. Gifted Child Quarterly, 28, 80-88.

Piechowski, M. M., Silverman, L. K., \& Falk, R. F. (1985). Comparison of intellectually and artistically gifted on five dimensions of mental functioning. Perceptual and Motor Skills, 60, 539-549.

Piirto, J., Montgomery, D., \& May, J. (2008). A comparison of Dabrowski's overexcitabilities by gender for American and Korean gifted students. High Ability Studies, 19, 141-153.

Rinn, A. N. Mendaglio, S., Rudasill, K. M., \& McQueen K. S. (2010). Examining the relationship between the overexcitabilities and self-concepts of gifted adolescents via multivariate cluster analysis. Gifted Child Quarterly, 54, 3-17.

Schmitt, N., \& Kuljanin, G. (2008). Measurement invariance: Review of practice and implications. Human Resource Management Review, 18, 210-222.

Schoot, Rens van de, Lugtig, P., \& Hox, J. (2012). A checklist for testing measurement invariance. European Journal of Developmental Psychology. 1-7, Retrieved July 5, 2015, from http://dx.doi.org/10.1080/17405629.2012.6867 40

Smith, S. (2006). The influence of gender and country of origin on the overexcitabilities of American and Korean high school students with high ability. Unpublished Master's thesis, Oklahoma State University, Stillwater, OK.

Tieso, C. L. (2007a). Overexitabilities: A new way to think about talent? Roeper Review, $29,232-239$.

Tieso, C. L. (2007b). Patterns of overexitabilities in identified gifted students and their parents: A hierarchical model. Gifted Child Quarterly, 51, 11-22.

Tillier, W. (2009). Dabrowski without the theory of positive disintegration just isn't Dabrowski. Roeper Review, 31, 123-126. 
Treat, A. (2006). Overexcitabilities in gifted sexuality diverse population. Journal of Secondary Gifted Education, 17(4), 244-257.

Vandenberg, R. J., \& Lance, C. E. (2000). A review and synthesis of the measurement invariance literature: Suggestions, practices, and recommendations for organizational research. Organizational Research Methods, 3(1), 4-70.

Warn, R. T. (2011). An investigation of measurement invariance across genders on the overexcitability Questionnaire-Two. Journal of Advanced Academic, 22(4), 578593.

Webb, J. T., Amend, E. R., Webb, N. E., Goerss, J., Beljan, P., \& Olenchak, F. R. (2005). Misdiagnosis and dual diagnosis of gifted children and adults: ADHD, Bipolar, $O C D$, Asperger's Depression, and other Disorders. USA: Great Potential Press, Inc.

Wu, A. D., Li, Z., \& Zumbo, B. D. (2007).

Decoding the meaning of factorial invariance and updating the practice of multi-group confirmatory factor analysis: A demonstration with TIMSS data. Practical Assessment, Research $\mathcal{E}$ Evaluation,12(3), 1-26. 